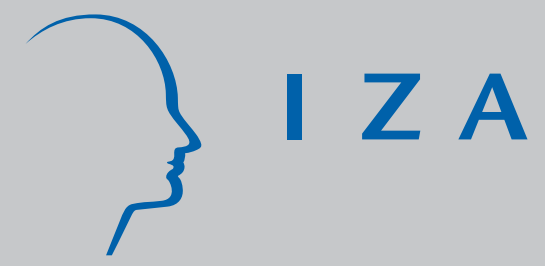

IZA DP No. 5733

The Effects of Cooperation:

A Structural Model of Siblings' Caregiving Interactions

Marike Knoef

Peter Kooreman

May 2011 


\title{
The Effects of Cooperation: A Structural Model of Siblings' Caregiving Interactions
}

\author{
Marike Knoef \\ Tilburg University \\ and Leiden University \\ Peter Kooreman \\ Tilburg University \\ and IZA
}

\author{
Discussion Paper No. 5733 \\ May 2011 \\ IZA \\ P.O. Box 7240 \\ 53072 Bonn \\ Germany \\ Phone: +49-228-3894-0 \\ Fax: +49-228-3894-180 \\ E-mail: iza@iza.org
}

Any opinions expressed here are those of the author(s) and not those of IZA. Research published in this series may include views on policy, but the institute itself takes no institutional policy positions.

The Institute for the Study of Labor (IZA) in Bonn is a local and virtual international research center and a place of communication between science, politics and business. IZA is an independent nonprofit organization supported by Deutsche Post Foundation. The center is associated with the University of Bonn and offers a stimulating research environment through its international network, workshops and conferences, data service, project support, research visits and doctoral program. IZA engages in (i) original and internationally competitive research in all fields of labor economics, (ii) development of policy concepts, and (iii) dissemination of research results and concepts to the interested public.

IZA Discussion Papers often represent preliminary work and are circulated to encourage discussion. Citation of such a paper should account for its provisional character. A revised version may be available directly from the author. 


\section{ABSTRACT \\ The Effects of Cooperation: A Structural Model of Siblings' Caregiving Interactions*}

This paper analyzes the decision making process of adult children to provide informal care to their parents. First, we develop a structural model to explain the amount of time that only children (without siblings) spend on providing care, taking into account opportunity costs in terms of time and money. The model is estimated using two datasets from 12 European countries and reveals the preferences of adult children for consumption, leisure and informal care. Although we assume that differences in behavior between children with and without siblings are due to dissimilar constraints only, by using only children we do not have to make assumptions about interactions between siblings in the structural model. In the presence of siblings, their choices also play a role in the caregiving decision. A central question is whether siblings make cooperative or noncooperative decisions. The second part of this paper aims to establish whether interactions between siblings are cooperative or noncooperative, by comparing predicted cooperative and noncooperative outcomes with observed outcomes. We use the structural parameter estimates from the first part of the paper and model the noncooperative outcomes using a Quantal Response Equilibrium. The results suggest that the nature of the interactions between siblings has a strong effect on the division of informal care between siblings. For almost three quarters of the families the noncooperative model has a better fit than the cooperative model. When the noncooperative families can be pushed into their cooperative outcome, their parents would on average receive $50 \%$ more informal care per week from their children, but this would reduce full-time labor supply by $5.7 \%$-points and increase part-time labor supply by $6.7 \%$.

JEL Classification: J22

Keywords: $\quad$ time allocation, (non)cooperation, structural modelling

Corresponding author:

Peter Kooreman

Department of Economics

Tilburg University

P.O.B. 90153

5000 LE Tilburg

The Netherlands

E-mail: p.kooreman@uvt.nl

\footnotetext{
${ }^{*}$ The authors thank Matthijs Kalmijn for his contribution in an early stage of the project and Netspar for financial support. We thank Hendri Adriaens, Rob Alessie, Katherine Carman, Michael Hurd, Bertrand Melenberg, Giacomo Pasini, Martin Salm and Arthur van Soest for comments and advice on computational issues. Financial support has been provided by Stichting Instituut GAK and Netspar.
} 


\section{Introduction}

When parents age, their adult children usually face deteriorating parental health and an increased need for care. For the children, the question arises how to balance the goal of appropriately caring for parents with other goals in life, such as work and own family. Governments, on the other hand, face the challenge how to reconcile the conflicting goals of encouraging the provision of care for the elderly by families, and encouraging (female) participation in the labor market.

A prerequisite for designing effective policies in this area is to understand the complex decision making process at the level of individual families. The outcome of the decision making process depends on a large number of factors, including the labor market potential and the own family situation of each adult child in the family, the availability of formal care, the distances between the parental home and each child's home and the health status of the parents. An additional important factor that has received only scant attention in the literature is the nature of the interactions between siblings, in particular whether it can be characterized as cooperative or non-cooperative.

The purpose of this paper is to analyze this complex process by developing a structural model in which adult children allocate their time to work, leisure, and care simultaneously. Our first contribution to the literature is that we estimate a structural model for children without siblings (only children), to learn about the preferences of adult children for informal care, without having to make assumptions about the nature of interactions between siblings. Thus our maintained assumption is that differences in behavior between children with and without siblings are due to dissimilar constraints only. In the model, preferences are characterized by a utility function defined over consumption, leisure, and the amount of care that parents receive from their children. Children face a time constraint and a budget constraint, which depend on the (potential) wage in the labor market, and the time and monetary costs of traveling to the parental home. As far as we know, this is the first study that extracts preferences with regard to informal care using only children, such that the results are not affected by interactions between siblings. Only Kotlikoff and Morris (1990) explicitly consider only children, but they analyze the living arrangement of an only child and a single parent. This study, instead, focuses on care arrangements, taking living arrangements as given. ${ }^{1}$

\footnotetext{
${ }^{1}$ There are some studies that model both care and living arrangements, e.g. Hoerger et al. (1996) and Pezzin and Schone (1999).
} 
Our second contribution to the literature is a first attempt to assess the nature of the interactions between siblings and investigate the potential welfare gains of cooperation between siblings. In the literature siblings are often ignored in the decision making process, or included only as an explanatory variable. However, as noted, among others, by Checkovich and Stern (2002) caregiving decisions among siblings are not independent and allowing for simultaneous decision making among siblings improves our understanding of caregiving decisions. The next question that arises is how these family decisions take place. Some studies that consider siblings assume that decisions are made noncooperatively (Hiedemann and Stern, 1999; Byrne et al., 2009; Callegaro and Pasini, 2008; Fontaine et al., 2009), while others assume a two-stage decision process in which siblings (1) decide whether to participate in caregiving or not, and (2) those who participate in caregiving make a cooperative care decision (Engers and Stern, 2002). This study computes cooperative as well as noncooperative equilibria between siblings using the estimated preference parameters from the structural model, and compares these equilibria to the observed outcomes found in the data. To do this, we have to make some assumptions. First, as mentioned before, siblings are assumed to have the same preferences as only children with regard to leisure, consumption, and the amount of informal care received by the parent. Secondly, we assume that own informal care and informal care provided by a sibling are perfect substitutes. Finally, we assume that siblings have their own time and budget constraints and that there are no financial transfers between siblings.

We bring the model to the data using the first two waves of the Survey of Health, Ageing and Retirement in Europe (SHARE). SHARE includes information on the distances between the parental and adult children's homes, labor market participation, the household situation of adult children and their parents, and the amount of time spent on caring for parents. Sources of identification of the econometric model include shocks in the health condition of parents between the two SHARE waves, and variation in characteristics and outcomes between waves and between adult children. SHARE does not contain wage and income data of the adult children. Therefore, we use the European Union Statistics on Income and Living Conditions (EU-SILC) as additional data to impute wage rates and other household income for the adult children.

The results show that for $71 \%$ of the siblings the noncooperative model has a better fit than the cooperative model. If it is possible to push these families into their cooperative equilibrium the amount of informal care can be increased, but this would reduce labor supply. 
The paper proceeds as follows. Section 2 discusses relevant literature on informal care giving. In section 3 we specify the structural model and explain the estimation strategy. Section 4 discusses the data, after which section 5 presents the estimation results. Section 6 considers the nature of the interactions between siblings (cooperative and noncooperative equilibria) and investigates the potential welfare gains of cooperation. Section 7 concludes.

\section{Literature Review}

In the economic, demographic, sociological, and psychological literature on the elderly, considerable attention has been paid to the degree to which children support their (elderly) parents. Support itself is usually distinguished into instrumental support on the one hand, and social and emotional support on the other hand (Hogan and Eggebeen, 1995; Silverstein and Bengtson, 1997). This study focuses on instrumental support, which includes practical help to parents (e.g., running errands, doing household work), help with personal care (e.g., washing, bathing, caring for when sick) and help with paperwork. Research shows that children often provide practical help to their parents. Even at later ages, however, parents in Europe more often help children than children help parents (Kohli, 1999). Hence, there hardly is a reversal of the flow of practical support exchange as parents age.

Another category of instrumental support is financial support. Financial support to parents is rarely given by children in western societies, except among immigrants. Bonsang (2007) found that only $2.6 \%$ of adult children in European countries provide financial assistance to their parents. In non-western societies, it is more common and often more obligatory that adult children financially support their parents (Frankenberg et al., 2002; Lee et al., 1994). Financial support from parents to children is more common. However, these financial transfers are mainly to children following further education or less well off children, such as those who are unemployed. As these motivations are not directly related to informal care giving, this study does not take financial transfers explicitly into account.

In the empirical economic literature we find reduced form models and structural models investigating (1) the extent to which informal care and formal care are complements or substitutes, (2) the factors that determine the provision of informal care, and (3) the dependence between informal care giving and labor supply.

If informal and formal care are substitutes, informal care can reduce home health care use and delay nursing home entry. Only then, governmental long term care expenditures can be reduced and labor shortages in the (long term) health care sector can be reduced, by increasing 
informal care. Bolin et al. (2008a) and Bonsang (2009) investigated this issue in European countries and found that informal care is a substitute for long term care, at least as long as the needs of the elderly are low and require unskilled type of care. For the U.S. Van Houtven and Norton (2004) also conclude that informal care and formal care are substitutes. On the other hand, the introduction of free formal personal care in Scotland in 2002 did not seem to have reduced informal care (Bell et al., 2006).

The models in the literature focus on a large number of potential determinants. Theoretically, these determinants can be distinguished into demand and supply variables. Demand variables are characteristics of parents which indicate the degree to which parents 'need' support from their children, such as a parent's health status, and whether the parent is living with a partner (Grundy, 2005; Klein Ikkink et al., 1999; Silverstein, 1995; Spitze and Logan, 1989). Living with a partner is related to less need for support by children, because the partner is the prime source of giving support to an elderly person (Dykstra, 1993).

Supply variables have to do with the child's costs and benefits of giving support. Research shows that there is variation among societies in the degree to which children respond to the need of their parents, with children in individualistic countries like Sweden and the Netherlands being less responsive (Kalmijn and Saraceno, 2008). We will therefore include country specific dummy variables to allow the preferences for informal care to differ across countries.

An important supply variable is time costs. Giving support and paying a visit are time intensive, especially if support also requires traveling, which usually is the case. There are also financial costs involved, but there is little evidence that the child's income situation affects contact or support (Klein Ikkink et al., 1999; Waite and Harrison, 1992). There are social status gradients in contact and support, but these have more to do with education and less with financial aspects of social status (Kalmijn and Dykstra, 2006).

The time budget of an adult child depends on whether the child has own children living in the home. Several authors have hypothesized that caring for one's own children competes with the support children give to their elderly parents. This phenomenon has been referred to as the 'sandwich generation'. There is indeed some evidence that the support daughters give to parents is negatively affected by having children (Klein Ikkink et al., 1999), but there is also evidence for a null effect (Eggebeen and Hogan, 1990). A complication is that having own children may also increase contact levels with the parent due to the grandparenting role (Kalmijn and Dykstra, 2006). This may be a reason why there are no consistent effects of having children on support.

Employment also affects children's time budget, and the opportunity costs of labor may 
influence the informal care decision. Several studies have investigated the relation between employment and informal care using different datasets and methods to correct for the potential endogeneity bias (caregivers may have different (unobserved) characteristics than non-caregivers, which influence both informal care and labor market decisions). The results are mixed. Wolf and Soldo (1994) find no evidence of reduced propensities to be employed, or of reduced conditional hours of work, due to the provision informal care. Others find that informal care reduces employment significantly among European men and women (Bolin et al., 2008b), and among U.S. women (Ettner, 1996). Ettner (1995) and Heitmueller and Michaud (2006) find that caregiving for coresidential parents reduces employment. As in Pezzin and Schone (1997, 1999), Byrne et al. (2009), and Callegaro and Pasini (2008) we will model the labor force decision and informal care decision jointly in a structural model. The results are important for understanding the conflict between women's increasing economic role in society on the one hand, and the increasing need for informal support to the elderly on the other hand (Kohli, 1999).

A final determinant of informal care has to do with family size and family interactions. The number of siblings in a family may have different effects. First, parents will need less help of each individual child when they have more children. In addition, children may shirk their responsibilities if there are many siblings who can do the work, such that the amount of informal care given by a sibling may depend negatively on the care of another sibling. On the other hand, in case of a strategic bequest motive (described by Bernheim and Summers, 1985), the amount of care given by a sibling depends positively on the care given by the other siblings. However, more recent studies do not support the bequest motive (Sloan et al., 1997; Perozek, 1998; Callegaro and Pasini, 2008). It has been found that siblings are each other's substitutes. The more siblings a child has, the less often the child visits the parent and the less often he or she gives support to the parent (Kalmijn, 2007; Kalmijn and Saraceno, 2008; Spitze and Logan, 1991). In addition to the number of siblings, the nature of the interactions between siblings play a role in informal care decisions. In the literature we do not find evidence about whether siblings behave cooperatively or noncooperatively. This study tries to establish the behavior of siblings using the preference parameters of only children which are obtained in a structural model.

\section{Structural Model}

This section describes the structural model we use to estimate the amount of time only children spend on providing informal care to their parents taking into account the key supply and demand 
factors discussed in the previous section. Section 3.1 deals with the specification of the model and describes the estimation strategy. Section 3.2 explains how we impute wage rates and other household income in the model, because SHARE contains no information about the wage rates and other household income of the adult children. We use a wage equation to impute wage rates and an income equation to impute remaining household income for the adult children in SHARE.

\subsection{Model specification}

We specify a structural model to explain the amount of time an adult child spends on paid work, care for parents, and other activities. In this study all activities other than paid work and care for parents are called leisure. As in Van Soest (1995), we formulate the model as a discrete choice problem. In this discrete choice problem adult children can choose between different combinations of labor, informal care, and leisure, which also lead to different levels of consumption. With regard to labor we distinguish full-time employment, part-time employment, and no employment. ${ }^{2}$ In the model fulltime employment is set to 36 hours of labor per week and part-time employment to 18 hours of labor per week. Concerning informal care we consider the choice to give no substantial amount of informal care, providing informal care between 1 and 4 hours a week on average (50\% of the informal care givers), between 4 and 8 hours a week (20\%) and providing more than 8 hours informal care a week (30\% of the informal care givers). In case no substantial amount of informal care is given, the hours of informal care in the model is set to zero. ${ }^{3}$ For the second informal care category (1-4 hours) we set the number of hours of informal care in the model to be 2 (the average) and the number of visits to one per week, for the second category (4-8 hours) the number of hours is six (the average) and visits are on a daily basis ${ }^{4}$. In the last category ( $>8$ hours per week) we set the number of hours of informal care to be $18^{5}$ and we assume that the parents are visited on a daily basis, which is also the median number of visits in this category. In total we thus have a choice set of 12 alternatives (3 labor market categories $\times 4$ informal care categories).

The child derives utility from leisure $\left(t_{l}\right)$, consumption $(c)$, and the amount of informal care

\footnotetext{
${ }^{2}$ These are the three categories available in the data.

${ }^{3}$ In the data there are 134 observations giving informal care between 0 and 1 hour per week. Most of them give less than 0.25 hours of informal care per week. These people fall in the category 'no substantial informal care'.

${ }^{4}$ The median number of visits in the 4-8 category is also seven per week.

${ }^{5}$ This is the median number of hours of informal care in the ' $>8$ ' category. The average number of hours of informal care in this category is 29 , but this is due to some individuals giving a very high number of hours of informal care.
} 
his parents receive $\left(t_{s}\right)$. We use the following quadratic utility function

$$
U(t)=t^{\prime} A t+t^{\prime} b
$$

where $t=\left(t_{l}, c, t_{s}\right)^{\prime}, A$ is a symmetric $3 \times 3$ matrix with entries $\alpha_{i j}(i, j=1,2,3)$ and $b=$ $\left(b_{l}, b_{c}, b_{s}\right)^{\prime}$. For the model to be economically rational, the marginal utility of consumption must be positive; see e.g. Van Soest and Stancanelli (2010). We will check whether this condition is satisfied in its estimated version. The marginal utility of informal care may be negative. ${ }^{6}$ We maximize the utility function subject to a time and budget constraint. The time and budget constraints are specified as

$$
\begin{aligned}
& t_{l}+t_{h}+t_{s}+(\tau d) K=T \\
& c+K p_{d} d=w t_{h}+\mu
\end{aligned}
$$

where

$$
\begin{aligned}
t_{h} & =\text { labor time (hours) } \\
K & =\text { number of visits (per week) } \\
d & =\text { distance to parent (return trip, } \mathrm{km} \text { ) } \\
\tau & =\text { travel time per kilometer (hours) } \\
T & =\text { total time (\# hours in one week) } \\
p_{d} & =\text { travel costs (per kilometer) } \\
w & =\text { wage (per hour) } \\
\mu & =\text { remaining household income }
\end{aligned}
$$

The time endowment $T$ is 168 hours per week. Remaining household income $(\mu)$ includes all income that is not earned by the adult child under consideration. It includes capital income, social transfers, and labor income of the partner (if present). We abstract from the fact that labor market choices of the adult children under consideration and their partners may be determined simultaneously. Furthermore, we assume wage rates ${ }^{7}$ and the geographical distance

\footnotetext{
${ }^{6}$ Estimates of Byrne et al. (2009) show that adult children care about their parents' health quality, suggesting that altruism may play an important role in the provision of informal care. However, they also show that informal care provision tends to be burdensome, which may explain why few family members provide care for elderly individuals.

${ }^{7}$ Bolin et al. (2008b) found no statistically significant wage-rate effects of informal care provision in Europe.
} 
between adult children and their parents to be exogenous. ${ }^{8}$

To take into account preference variation across adult children, the vectors in $b$ are functions of observed and unobserved characteristics of the adult children and their parents ${ }^{9}$

$$
\begin{aligned}
& b_{l}=X_{l} \beta_{l}+u_{l} \\
& b_{c}=X_{c} \beta_{c}+u_{c} \\
& b_{s}=X_{s} \beta_{s}+u_{s} .
\end{aligned}
$$

$X_{l}$ and $X_{c}$ contain characteristics which are likely to influence the amount of leisure time and consumption the adult child prefers, such as the age, gender, education, number of children, and marital status of the adult child. $X_{s}$ includes variables influencing the preference for giving informal care to parents, namely the health position of the parents, whether both parents are alive and the gender of the parent when the parent is single, the (average) age of the parents, the gender of the child, country specific dummy variables, and the number of children of the adult child. Also education is included in the matrix $X_{s}$, because higher educated children may have different value orientations (Kalmijn, 2006). Random preferences due to unobserved characteristics are incorporated through the terms $u_{l}, u_{c}$, and $u_{s}$. They capture time invariant unobserved heterogeneity. For example, $u_{s}$ may capture the three motives that are, in addition to observed characteristics, important in explaining social support: reciprocity, altruism, and norms of responsibility. ${ }^{10}$ We assume $u=\left(u_{l}, u_{c}, u_{s}\right)$ to be distributed jointly normal with mean zero and covariance $\Sigma_{u}$

$$
\left[\begin{array}{l}
u_{l} \\
u_{c} \\
u_{s}
\end{array}\right] \sim N\left(\left[\begin{array}{l}
0 \\
0 \\
0
\end{array}\right],\left[\begin{array}{ccc}
\sigma_{l}^{2} & \sigma_{l, c} & \sigma_{l, s} \\
\sigma_{l, c} & \sigma_{c}^{2} & \sigma_{c, s} \\
\sigma_{l, s} & \sigma_{c, s} & \sigma_{s}^{2}
\end{array}\right]\right) .
$$

In addition, we introduce random disturbances to the utilities of the twelve choice opportunities in the same way as in the multinomial logit model

$$
\begin{aligned}
& U_{j}=U\left(t_{l}, c, t_{s}\right)+\epsilon_{j} \quad j=1, \ldots, 12 \\
& \epsilon_{j} \sim E V(I) \quad j=1, \ldots, 12 \quad \epsilon_{1}, \ldots, \epsilon_{12} \text { independent }
\end{aligned}
$$

\footnotetext{
${ }^{8}$ Charles and Sevak (2005) tested whether children's location endogenously responds to parent's health but found no evidence of this.

${ }^{9}$ While we adopt a specific parametric form for the utility function, preferences are identified nonparametrically. In general, preferences are not fully identified in a model that disaggregates nonlabor time use since each nonlabor time use category has the same price, the wage rate (Hicks aggregate commodity theorem). However, in our case the price of informal care exceeds the price of pure leisure because of travel costs. Moreover, the price ratio varies across families as wages and distances to parents vary.

${ }^{10}$ These three motives are investigated in the sociological literature (e.g. Kohli and Künemund, 2003, and Kalmijn, 2010). Kalmijn (2010) found that altruism is relatively important for parents to support their children, however, for adult children, reciprocity and norms of responsibility appear to be relatively more important.
} 
leading to the familiar logit choice probabilities

$$
\begin{aligned}
& P\left(U_{j}>U_{k} \text { for all } k \neq j \mid X, d, w, \mu, u\right)= \\
& \exp \left(U\left(t_{j}\right)\right) / \sum_{k=1}^{12} \exp \left(U\left(t_{k}\right)\right) .
\end{aligned}
$$

Substituting the utility function (1) and the time and budget constraint (2), equation (6) becomes

$$
\begin{aligned}
& P\left(U_{j}>U_{k} \text { for all } k \neq j \mid X, d, w, \mu, u\right)= \\
& \exp \left(t_{j}^{\prime} A t_{j}+t_{j}^{\prime} b\right) / \sum_{k=1}^{12} \exp \left(t_{k}^{\prime} A t_{k}+t_{k}^{\prime} b\right),
\end{aligned}
$$

where $t_{j}=\left(t_{l j}, c_{j}, t_{s j}\right)$ and $t_{l j}$ and $c_{j}$ are defined by

$$
\begin{aligned}
t_{l j} & =T-t_{h j}-t_{s j}-(\tau d) K_{j} \\
c_{j} & =w t_{h j}+\mu-K_{j} p_{d} d .
\end{aligned}
$$

Equation (7) presents the probability that a certain combination of $\left(t_{l}, c, t_{s}\right)$ is chosen, given observed and unobserved characteristics. The disturbances $\epsilon_{j}$ can be interpreted as optimization errors: adult children choose a combination of $\left(t_{l}, c, t_{s}\right)$ that is close to optimal, rather than always fully optimal. This may be due to errors in the perception of the utilities of the set of alternatives. In contrast, the random effects $\left(u_{l}, u_{c}, u_{s}\right)$ are known by the adult child (but unobserved to the researcher). We estimate the model parameters using maximum likelihood. The likelihood contribution of an individual $i$ who chooses alternative $j$ is

$$
\begin{aligned}
& L_{i}\left(\alpha, \beta, \Sigma_{u} \mid X, d, w, \mu\right) \\
& =\int_{-\infty}^{+\infty} \int_{-\infty}^{+\infty} \int_{-\infty}^{+\infty} P\left(U_{j}>U_{k} \text { for all } k \neq j \mid X, d, w, \mu, u\right) p(u) d u
\end{aligned}
$$

where $p(u)$ is the density of vector $u$. The three dimensional integral can be approximated using simulations (simulated maximum likelihood). Using $R$ simulations, the likelihood contribution of equation (9) becomes

$$
L_{i R}\left(\alpha, \beta, \Sigma_{u} \mid X, d, w, \mu\right)=\frac{1}{R} \sum_{r=1}^{R} P\left(U_{j}>U_{k} \text { for all } k \neq j \mid X, d, w, \mu, u^{r}\right),
$$

where the draws $u^{r}, r=1 \ldots R$ are from a trivariate normal distribution with mean zero and variance $\Sigma_{u}$. Most of the adult children are observed two times (wave 1 and wave 2). The likelihood contribution of an adult child who is observed in both waves, and chooses alternative 
$j$ in wave 1 and alternative $h$ in wave 2 is

$$
\begin{aligned}
& L_{i R}\left(\alpha, \beta, \Sigma_{u} \mid X, d, w, \mu\right)= \\
& \frac{1}{R} \sum_{r=1}^{R} P\left(U_{j 1}>U_{k 1} \text { for all } k \neq j \mid X_{1}, d_{1}, w_{1}, \mu_{1}, u^{r}\right) \\
& * P\left(U_{h 2}>U_{k 2} \text { for all } k \neq h \mid X_{2}, d_{2}, w_{2}, \mu_{2}, u^{r}\right),
\end{aligned}
$$

so that the unobserved characteristics are the same in both waves.

A draw $u^{r}$ can be obtained by taking 3 (pseudo-random) draws from a standard normal distribution (let's call them $\left.\theta=\left(\theta_{l}, \theta_{c}, \theta_{s}\right)^{\prime}\right)$ and then calculate $\left(u_{l}^{r}, u_{c}^{r}, u_{s}^{r}\right)^{\prime}=L \theta$. Here, $L$ is the Choleski factor of $\Sigma_{u}$ (the unique lower triangular matrix such that $L L^{\prime}=\Sigma_{u}$ ). ${ }^{11}$

Integrals can be approximated with fewer draws $(R)$ when using Halton draws instead of pseudo-random draws. This is because Halton sequences provide more coverage of the density which has to be integrated. For more information about the derivation of Halton sequences see for example Train (2003), or Drukker and Gates (2006), who discuss the advantages of Halton sequences when using simulations to approximate integrals numerically.

\subsection{Modeling wage rates and remaining household income}

In SHARE wage rates $(w)$ and remaining household income $(\mu)$ of the adult children are unknown, therefore we use predictions from a wage equation ${ }^{12}$ and an equation for remaining household income. Both equations are estimated using the 'European Union Statistics on Income and Living Conditions' (EU-SILC).

In EU-SILC we can only observe wages for workers. However, the working population is probably not a random subsample from the population as people with comparatively high wages (conditional on, for example, their education level) are more likely to work. There may be unobservables that influence the decision to participate, as well as the wage rate. A commonly used method to deal with this sample selection is the method by Heckman (1979). Heckman takes selection bias into account by adding an equation which models the participation decision, and allowing for nonzero correlation between the wage and the participation equation.

\footnotetext{
${ }^{11} u$ is normally distributed because the sum of normals is normal. Furthermore, the covariance of $u$ is $\Sigma_{u}$ because $\operatorname{Var}(u)=E\left(u u^{\prime}\right)=E\left(L \theta(\theta L)^{\prime}\right)=L E\left(\theta \theta^{\prime}\right) L^{\prime}=L \operatorname{Var}(\theta) L^{\prime}=L I L^{\prime}=L L^{\prime}=\Sigma_{u}$ (Train, 2003).

${ }^{12} \mathrm{We}$ assume wage rates to be independent of the provision of informal care. This is consistent with the results of Bolin et al. (2008b), who did not find any statistically significant wage-rate effects of informal care provision.
} 
We estimate the following Heckman model, for each country separately

$$
\begin{aligned}
\ln \left(w_{i}^{*}\right) & =X_{w i} \beta_{w}+v_{w i} \\
p_{i}^{*} & =X_{p i} \beta_{p}+v_{p i} \\
w_{i} & =w_{i}^{*} \quad \text { if } p_{i}^{*}>0 \\
w_{i} & =0 \quad \text { if } p_{i}^{*} \leq 0
\end{aligned}
$$

where $(12 \mathrm{a})$ is the wage equation and $(12 \mathrm{~b})$ is the (probit type) participation equation. $X_{w i}$ and $X_{p i}$ contain personal characteristics such as age, gender, and the education level. Generally an exclusion restriction is required to generate credible estimates from the Heckman selection model. Therefore, we include dummy variables for having children in the participation equation, but exclude these from the wage equation. We assume that $v_{p}$ and $v_{w}$ are bivariate normal distributed

$$
\left[\begin{array}{l}
v_{p} \\
v_{w}
\end{array}\right] \sim N\left(\left[\begin{array}{l}
0 \\
0
\end{array}\right],\left[\begin{array}{cc}
1 & \sigma_{w p} \\
\sigma_{w p} & \sigma_{w}^{2}
\end{array}\right]\right)
$$

and we estimate the parameters using FIML. As for a probit model, the normalization $\sigma_{p}^{2}=1$ is used since only the sign of $p_{i}^{*}$ is observed. For remaining household income $(\mu)$ we also estimate an equation using a standard OLS regression, for each country and for men and women separately

$$
\ln \left(\mu_{i}\right)=X_{\mu i} \beta_{\mu}+v_{\mu i},
$$

where $X_{\mu i}$ contains personal characteristics such as age, marital status, and the education level.

In the structural model, introduced in section 3.1, we take into account that wage rates and remaining household income are predicted with error. Using the estimated variances of the errors in the wage equations and the remaining household income equations $\left(\sigma_{w}^{2}\right.$ and $\left.\sigma_{\mu}^{2}\right)$ we integrate the prediction errors out. Van Soest (1995) also uses estimated standard deviations of the errors in the wage equation to account for prediction errors.

When we take into account prediction errors, the likelihood contribution in equation (9) of an individual who chooses alternative $j$ becomes

$$
\begin{aligned}
& L\left(\alpha, \beta, \Sigma_{u} \mid X, d, \beta_{w}, \sigma_{w}, \beta_{\mu}, \sigma_{\mu}\right) \\
& =\iiint \iint_{-\infty}^{+\infty} P\left(U_{j}>U_{k} \text { for all } k \neq j \mid X, d, w, \mu, u\right) p(u) p(w) p(\mu) d u d w d \mu .
\end{aligned}
$$

So that equation (10) becomes

$$
\begin{aligned}
& L_{i R}\left(\alpha, \beta, \Sigma_{u} \mid X, d, \beta_{w}, \sigma_{w}, \beta_{\mu}, \sigma_{\mu}\right)= \\
& \frac{1}{R} \sum_{r=1}^{R} P\left(U_{j}>U_{k} \text { for all } k \neq j \mid X, d, w^{r}, \mu^{r}, u^{r}\right),
\end{aligned}
$$


where

$$
w^{r}=\exp \left(X_{w}^{\prime} \beta_{w}+v_{w}^{r}\right)
$$

and $v^{r}$ is a draw from the normal distribution with variance $\sigma_{w}^{2}$. In the same way

$$
\mu^{r}=\exp \left(X_{\mu}^{\prime} \beta_{\mu}+v_{\mu}^{r}\right)
$$

where $v_{\mu}^{r}$ is a draw from the normal distribution with variance $\sigma_{\mu}^{2}$.

For most countries the estimates of $\sigma_{w p}$ in the EU-SILC data are not significant, which indicates that selection with regard to unobservables is not very important. We therefore do not take into account correlations between $v_{w}, v_{\mu}$ and the unobserved characteristics $\left(u_{l}, u_{c}, u_{s}\right)$.

\section{Data}

This section describes the data we use to estimate the parameters of the model. Section 4.1 describes the Survey of Health, Ageing and Retirement in Europe (SHARE) and section 4.2 the 'European Union Statistics on Income and Living Conditions' (EU-SILC).

\subsection{SHARE}

SHARE is a multidisciplinary database of microdata on health, socio-economic status and social and family networks of individuals aged 50 and older in Europe. Data were collected in 2004/2005 (wave 1) and 2006/2007 (wave 2) by face-to-face computer-aided personal interviews (CAPI), plus a self-completion drop-off part with questions that command more privacy. This study uses 13 countries that have contributed data to SHARE. They represent various regions in Europe, ranging from Scandinavia (Denmark and Sweden) through Central Europe (Austria, France, Germany, Belgium, and the Netherlands) to the Mediterranean (Spain, Italy and Greece). In the second wave two 'new' EU member states have contributed data to SHARE (Czech Republic and Poland). Other countries available in SHARE that we do not use in this study are Israel and Ireland. We do not use these countries because they are not represented in the EU-SILC data, which we describe in the next section.

There are several papers using SHARE to study informal care giving. Most of these studies use the respondents as providers of informal care (e.g. Bonsang, 2007, 2009, and Bolin et al., 2008a,b). This study considers the respondents in their role as (the potential) receiver of informal care. Crespo and Mira (2010) call this the 'parents-sample' as the respondents are the elderly parents. The reason for using the 'parents-sample' is that we need information on all 
siblings within a family. The respondents (in our case 'the parents') give information about all their children that are still alive (sex, year of birth, geographical distance between the children and their parents, education, marital status, number of children, the employment status of the children, and the amount of informal care they receive from their children). If we would consider the respondents as the providers of informal care, there would be no information on the amount of care the siblings of the respondents give to their parents. The health situation of the parents provides a measure for the amount of care parents need. SHARE provides a lot of health related variables, such as self-reported health, limitations in activities of daily living (ADL and IADL), mental health, diagnosed chronic conditions, whether people are suffering from several symptoms and limitations in functioning (e.g. measures by grip strength and walking speed). In this study, however, we use self-reported health which has the lowest number of missings. The parents are asked to rate their health on a five-point scale, ranging from very good to very poor (wave 1) or from excellent to poor (wave 2).

We select all respondents with one or two adult children. Furthermore, our interest is on children who are 40 years or older, as these children are most likely to be involved in personal care for their elderly parents. Following McGarry (1999), Bonsang (2007), and Norton and Van Houtven (2006) we omit households where children are living in the same household as the respondent, because there is no detailed information on informal care giving within households. For the same reason we exclude respondents where grand-children, siblings, and other nonrelatives are living in the same household as the respondent. Families with one or two selfemployed adult children are excluded, because we have no information about the number of hours that self-employed people work. Also families where one or both children have the daily activity 'sick' are excluded, as they may not be able to give informal care. After excluding respondents for whom key information is missing, we end up with 2253 respondents with one adult child and 2891 respondents with two adult children.

Table 1 shows the amount of informal care and the number of adult children per country. Informal care includes practical household help (e.g. household chores, shopping and home repairs), personal care (e.g. dressing, bathing, eating) and help with paperwork. Adults report whether their children help them on an almost daily basis, weekly, monthly or less often. Furthermore, they were asked to give an estimate of the number of hours of informal care received on a typical day, week, month or year. We transform these answers to a variable measuring the average amount of informal care that adults receive from their children per week. We define people to be involved in informal care when they give one hour or more informal care per week. 
In Germany, Greece, Czechia and Poland a lot of people are involved in informal care giving (more than $15 \%$ of the only children and siblings). Conditional on being involved in informal care, children in Mediterranean countries give relatively many hours of informal care, whereas the children in Denmark, The Netherlands, and Sweden give a relatively small number of hours of informal care. When we compare only children and siblings, we find that in general only children are more often involved in informal care giving than siblings and that they also provide more hours of informal care. This suggests that the hours of care provided by a sibling are a substitute for someone's own informal care.

Table 1: Informal care per country ${ }^{\mathrm{a}}$

\begin{tabular}{|c|c|c|c|c|c|c|}
\hline Country & only child & $\begin{array}{r}\% \text { informal } \\
\text { care }\end{array}$ & \# hrs & 1 sibling & $\begin{array}{r}\% \text { informal } \\
\text { care }\end{array}$ & \# hrs \\
\hline Austria & 218 & 14.7 & 15.9 & 438 & 12.3 & 6.9 \\
\hline Germany & 294 & 19.0 & 17.3 & 572 & 15.0 & 6.3 \\
\hline Sweden & 217 & 10.6 & 7.1 & 674 & 7.6 & 5.9 \\
\hline Netherlands & 115 & 7.8 & 3.0 & 442 & 4.3 & 4.8 \\
\hline Spain & 99 & 13.1 & 17.2 & 308 & 9.7 & 19.5 \\
\hline Italy & 167 & 12.0 & 18.4 & 338 & 8.6 & 12.8 \\
\hline France & 263 & 14.1 & 10.0 & 508 & 9.6 & 6.2 \\
\hline Denmark & 134 & 11.2 & 4.5 & 512 & 6.3 & 6.8 \\
\hline Greece & 213 & 19.7 & 17.1 & 804 & 19.5 & 12.5 \\
\hline Belgium & 318 & 20.1 & 5.8 & 528 & 8.1 & 10.8 \\
\hline Czechia & 165 & 24.2 & 11.8 & 450 & 29.6 & 10.7 \\
\hline Poland & 50 & 16.0 & 16.5 & 208 & 16.8 & 5.1 \\
\hline Total & 2253 & 15.9 & 12.2 & 5782 & 12.4 & 9.5 \\
\hline
\end{tabular}

Table 2 presents information about informal care giving and the geographical distances between children and their parents. The higher the distance between children and their parents, the higher the traveling time and costs, and the lower the fraction of people involved in informal care. It appears that the distribution of only children and siblings among the categories is about the same (so that only children do in general not live closer or further away from their parents than siblings). 
Table 2: Distance and informal care ${ }^{\mathrm{a}}$

\begin{tabular}{|l|rrr|rrr|}
\hline Distance & only child & $\begin{array}{r}\text { \% inf. } \\
\text { care }\end{array}$ & \# hrs & 1 sibling & $\begin{array}{r}\text { \% inf. } \\
\text { care }\end{array}$ & \# hours \\
\hline same building & 9.8 & 29.0 & 15.7 & 7.1 & 31.0 & 12.4 \\
$\leq 1$ kilometer & 17.2 & 20.7 & 11.0 & 15.3 & 19.1 & 12.3 \\
1-5 kilometers & 18.8 & 19.9 & 8.1 & 21.0 & 15.9 & 8.3 \\
5-25 kilometers & 25.6 & 15.9 & 13.1 & 23.2 & 10.5 & 6.3 \\
25-100 kilometers & 12.6 & 9.9 & 13.3 & 15.3 & 6.8 & 5.7 \\
100-500 kilometers & 10.0 & 4.4 & 24.3 & 11.1 & 3.6 & 6.5 \\
$\geq 500$ kilometers & 3.0 & 0.0 & - & 3.3 & 1.1 & 86.0 \\
$\geq 500$ kilometers & 3.0 & 1.5 & 1.9 & 3.7 & 1.4 & 1.4 \\
and another country & & & & & & \\
\hline Total & 100 & 15.9 & 12.2 & 100 & 12.4 & 9.5 \\
\hline
\end{tabular}

${ }^{\text {a }}$ Percentage of children involved in informal care and the number of hours of informal care, conditional on giving any informal care, per distance category.

Table 3: Health and informal care ${ }^{\mathrm{a}}$

\begin{tabular}{|l|rrr|rrr|}
\hline Health & only child & $\begin{array}{r}\text { \% inf. } \\
\text { care }\end{array}$ & \# hrs & $\begin{array}{r}\text { 1 sibling } \\
\text { \% inf. }\end{array}$ & \# hours \\
& & & & \\
\hline Father, good / very good & 8.7 & 6.1 & 4.5 & 7.7 & 6.3 & 13.5 \\
Father, fair & 4.9 & 19.8 & 9.6 & 5.9 & 12.4 & 5.0 \\
Father, poor & 2.4 & 34.0 & 15.9 & 2.3 & 23.5 & 8.4 \\
Mother, good / very good & 21.3 & 16.4 & 7.6 & 22.8 & 12.2 & 7.1 \\
Mother, fair & 17.8 & 24.2 & 9.8 & 15.0 & 19.5 & 10.1 \\
Mother, poor & 8.5 & 33.3 & 22 & 7.1 & 26.5 & 12.1 \\
Both poor, or poor and fair & 5.0 & 20.5 & 23.3 & 5.3 & 21.8 & 14.6 \\
Both fair, or fair and good & 15.6 & 6.5 & 7.2 & 17.5 & 5.9 & 7.9 \\
Both good / very good & 12.4 & 2.5 & 7.1 & 13.0 & 3.1 & 3.8 \\
Father poor, mother good & 1.7 & 12.8 & 2.9 & 1.7 & 10.4 & 5.6 \\
Father good, mother poor & 1.6 & 25.0 & 11.8 & 1.8 & 18.3 & 11.1 \\
\hline Total & 100 & 15.9 & 12.2 & 100 & 12.4 & 9.5 \\
\hline
\end{tabular}

a Percentage of children involved in informal care and the number of hours of informal care, conditional on giving any informal care, per health status of the elderly parent. In the first three categories the adult child only has a father, in the fourth to the sixth category the adult child only has a mother, and in the last five categories the adult child has a father and a mother. 
As expected, the provision of informal care is higher for children with parents in bad health than for children with parents in good health (table 3 ). In the analysis we distinguish single parents and parents living with a partner, as parents may provide informal care to each other when they are both alive. It appears that when the mother of a child is in poor health and the father is in good health there is more informal care from adult children than when the father is in poor health and the mother is in good health. The reason may be that men in these generations have less homework skills than women.

Table 4: Daily activity and informal care ${ }^{\mathrm{a}}$

\begin{tabular}{|l|rrr|rrr|}
\hline Daily activity & only child & $\begin{array}{r}\text { \% informal } \\
\text { care }\end{array}$ & \# hrs & 1 sibling & $\begin{array}{r}\text { \% informal } \\
\text { care }\end{array}$ & \\
\hline full-time work & 67.2 & 13.4 & 8.3 & 73.6 & 11.0 & 7.8 \\
part-time work & 8.2 & 15.2 & 7.6 & 8.8 & 11.2 & 5.9 \\
unemployed & 5.5 & 17.1 & 11.0 & 3.0 & 16.8 & 13.2 \\
in education & 0.6 & 7.1 & 14.0 & 0.3 & 0.0 & - \\
parental leave & 0.3 & 0.0 & - & 0.1 & 0.0 & - \\
(early) retirement & 8.1 & 31.1 & 20.4 & 5.4 & 26.4 & 10.9 \\
homemaker & 9.2 & 21.7 & 21.8 & 8.1 & 17.3 & 18.8 \\
other & 0.9 & 20.0 & 25.1 & 0.8 & 0.0 & - \\
\hline Total & 100 & 15.9 & 12.2 & 100 & 12.4 & 9.5 \\
\hline
\end{tabular}

${ }^{a}$ Percentage of children involved in informal care and the number of hours of informal care, conditional on giving any informal care, per daily activity of the adult child.

Table 4 shows the amount of informal care by the daily activity of the child. It is interesting to see that the amount of informal care does not differ much between children who are full-time employed and children who are part-time employed. Children who are (early) retired or are looking after home are most often involved in informal care. However, note that retired persons have relatively older parents, who are more often in bad health. Finally, women are more often involved in informal care than men and often provide more hours of informal care (table 5). 
Table 5: Gender ${ }^{\mathrm{a}}$

\begin{tabular}{|l|rrr|rrr|}
\hline Gender & only child & $\begin{array}{r}\text { \% informal } \\
\text { care }\end{array}$ & \# hrs & 1 sibling & $\begin{array}{r}\text { \% informal } \\
\text { care }\end{array}$ & \\
\hline Female & 53.8 & 17.7 & 14.1 & 51.9 & 14.8 & 9.9 \\
Male & 46.2 & 13.8 & 9.4 & 48.1 & 9.8 & 8.8 \\
\hline Total & 100 & 15.9 & 12.2 & 100 & 12.4 & 9.5 \\
\hline
\end{tabular}

${ }^{\text {a }}$ Percentage of children involved in informal care and the number of hours of informal care, conditional on giving any informal care, per gender of the adult child.

\subsection{EU-SILC}

The wage equation and the equation for remaining household income, described in section 3.2, are estimated using EU-SILC data. EU-SILC contains microdata on income, poverty, social exclusion and living conditions in Europe. It comprises information of surveys and registers from the EU member states. We select people up to age 76 and omit households who receive income out of self-employment or who are permanently sick or disabled (just as in SHARE). Furthermore, we exclude observations which have missings for one or more of the variables in the model. We end up with 55.100 observations, which are described in table 6 . 
Table 6: Descriptives EU-SILC

\begin{tabular}{|c|c|c|c|c|c|c|c|}
\hline & AT & $\mathrm{BE}$ & $\mathrm{CZ}$ & $\mathrm{DE}$ & DK & ES & FR \\
\hline Male $(\%)$ & 49 & 48 & 47 & 46 & 49 & 47 & 48 \\
\hline Age (mean) & 45 & 43 & 46 & 47 & 45 & 43 & 43 \\
\hline Primary education (\%) & 1 & 14 & 0 & 2 & 0 & 33 & 12 \\
\hline Lower secondary education (\%) & 24 & 18 & 19 & 16 & 29 & 22 & 13 \\
\hline (Upper) secondary education (\%) & 53 & 34 & 69 & 46 & 43 & 21 & 47 \\
\hline Post secondary non-tertiary education (\%) & 9 & 2 & 1 & 6 & 0 & 1 & 2 \\
\hline Tertiary education (\%) & 13 & 31 & 12 & 30 & 28 & 23 & 26 \\
\hline Man with partner (\%) & 35 & 32 & 32 & 32 & 38 & 31 & 34 \\
\hline Woman with partner (\%) & 34 & 35 & 32 & 31 & 37 & 33 & 32 \\
\hline Man with child (\%) & 22 & 24 & 17 & 21 & 23 & 24 & 25 \\
\hline Woman with child (\%) & 23 & 26 & 19 & 25 & 25 & 24 & 26 \\
\hline Net wage rate (mean) & 10 & 11 & 2 & 10 & 14 & 8 & 11 \\
\hline Nonlabor income (mean) & 27413 & 24240 & 5990 & 24718 & 28575 & 18717 & 24010 \\
\hline \multirow[t]{2}{*}{$\mathrm{N}$} & 1488 & 1346 & 1095 & 6028 & 1422 & 7171 & 3221 \\
\hline & GR & IT & NL & PL & $\mathrm{SE}$ & & Total \\
\hline Male (\%) & 44 & 47 & 51 & 46 & 50 & & 47 \\
\hline Age (mean) & 43 & 46 & 45 & 42 & 43 & & 44 \\
\hline Primary education (\%) & 28 & 27 & 9 & 17 & 9 & & 18 \\
\hline Lower secondary education (\%) & 13 & 29 & 24 & 7 & 16 & & 20 \\
\hline (Upper) secondary education (\%) & 36 & 32 & 37 & 60 & 42 & & 41 \\
\hline Post secondary non-tertiary education (\%) & 5 & 5 & 3 & 3 & 5 & & 4 \\
\hline Tertiary education (\%) & 19 & 7 & 27 & 13 & 28 & & 18 \\
\hline Man with partner (\%) & 28 & 30 & 40 & 30 & 38 & & 32 \\
\hline Woman with partner (\%) & 32 & 32 & 35 & 33 & 37 & & 33 \\
\hline Man with child (\%) & 22 & 21 & 25 & 27 & 27 & & 23 \\
\hline Woman with child $(\%)$ & 25 & 22 & 21 & 31 & 26 & & 25 \\
\hline Net wage rate (mean) & 7 & 9 & 12 & 2 & 10 & & 9 \\
\hline Nonlabor income (mean) & 15475 & 22161 & 22036 & 4835 & 23742 & & 18709 \\
\hline $\mathrm{N}$ & 1345 & 14155 & 6007 & 10464 & 1358 & & 55100 \\
\hline
\end{tabular}

\section{Estimation results}

This section presents the estimation results of the wage equation, the equation for remaining household income, and the parameters of the structural model. We start with the estimation 
results of the wage equation and the equation for remaining household income, since these are needed as input to estimate the parameters of the structural model.

\subsection{Wage equation and remaining household income}

Wage equations are estimated for every country separately. Table 7 describes the wage equation of Sweden. The wage equations of all other countries are estimated in a similar way and are available on request.

Table 7 shows that wage rates increase with age and are significantly higher for people with a high education level. $\sigma_{w p}$ is not significantly different from zero, indicating that sample selection is no significant issue. This also holds for most of the other countries. Due to measurement errors in the wage rates, the standard deviation of the errors in the wage equation may be overestimated..$^{13}$

Table 8 shows the estimation results of remaining household income for Sweden. Again, the equations of the other countries are estimated in a similar way and are available on request. Remaining household income increases with age. Furthermore, in Sweden remaining household income is not significantly different for different education categories. Next, we will use the wage equations and the equations for remaining household income from EU-SILC to estimate the parameters of the structural model.

\subsection{Estimation results structural model}

Table 9 presents the estimation results of the structural model. ${ }^{14}$ This section first describes the parameter estimates related to the preferences for informal care $\left(t_{s}\right)$. With regard to informal care the results show significant decreasing returns to scale ( $\alpha_{s s}$ is significantly negative). Furthermore, the interaction term $\alpha_{l s}$ is significantly positive, meaning that when the amount of informal care is already high, the utility of an extra hour of leisure increases. When parents are in bad health they need more attention and the estimates show that this increases the preference for informal care. The preference for informal care is highest when a single living father or mother has a poor health status, when both parents are in poor health, or when the mother has a poor health condition and the father is in good health. On the other hand,

\footnotetext{
${ }^{13}$ A sensitivity analysis, in which we for example multiply $\sigma_{w}$ by 0.8 for all countries, indicates that this does not influence the structural estimation results very much.

${ }^{14}$ Our estimation procedure uses 25 drawings. Estimation is computer intensive. Other studies with these kind of models have used for example 5 or 10 drawings which produce qualitatively similar results (Van Soest, 1995) or 10 drawings (Van Soest and Stancanelli, 2010).
} 
Table 7: Estimation results wage equation Sweden, sample selection model ${ }^{\mathrm{a}}$

\begin{tabular}{|c|c|c|}
\hline Equation 1: $\ln$ (wage rate) & Coefficient & St. error \\
\hline Man & 0.157 & 0.105 \\
\hline Age & 0.019 & 0.017 \\
\hline $\mathrm{Age}^{2} / 100$ & -0.010 & 0.020 \\
\hline Primary education & -0.070 & 0.109 \\
\hline Lower secondary education & -0.057 & 0.083 \\
\hline (Upper) secondary education & 0.000 & - \\
\hline Post secondary non-tertiary education & 0.051 & 0.089 \\
\hline Tertiary education & 0.109 & 0.046 \\
\hline Man with partner & 0.073 & 0.088 \\
\hline Women with partner & -0.092 & 0.082 \\
\hline Intercept & 1.458 & 0.368 \\
\hline \multicolumn{3}{|l|}{ Equation 2: participation decision } \\
\hline Man & -0.069 & 0.196 \\
\hline Age 15-29 & 0.000 & - \\
\hline Age 30-39 & 1.045 & 0.157 \\
\hline Age 40-49 & 1.010 & 0.143 \\
\hline Age 50-59 & 1.147 & 0.166 \\
\hline Age $\geq 60$ & -1.193 & 0.155 \\
\hline Primary education & -0.351 & 0.163 \\
\hline Lower secondary education & -0.962 & 0.130 \\
\hline (Upper) secondary education & 0.000 & - \\
\hline Post secondary non-tertiary education & -0.355 & 0.194 \\
\hline Tertiary education & 0.090 & 0.117 \\
\hline Man with partner & 0.612 & 0.152 \\
\hline Woman with partner & 0.574 & 0.145 \\
\hline Man with child & -0.022 & 0.144 \\
\hline Woman with child & -0.514 & 0.151 \\
\hline Intercept & 0.206 & 0.169 \\
\hline$\rho$ & 0.016 & 0.157 \\
\hline$\sigma_{w}$ & 0.615 & 0.014 \\
\hline$\sigma_{w p}=\rho \sigma_{w}$ & 0.010 & 0.097 \\
\hline $\mathrm{N}$ & 1358 & \\
\hline Censored observations & 422 & \\
\hline Uncensored observations & 936 & \\
\hline Log likelihood & -1374.725 & \\
\hline
\end{tabular}


Table 8: Estimation results remaining household income, Sweden ${ }^{\mathrm{a}}$

\begin{tabular}{lrrrr}
\hline $\ln ($ remaining household income) & \multicolumn{3}{c}{ Men } & \multicolumn{2}{c}{ Women } \\
\hline Age & Coefficient & St. error & Coefficient & St. error \\
Age $^{2}$ & -0.097 & 0.023 & -0.040 & 0.023 \\
Primary education & 0.001 & 0.000 & 0.001 & 0.000 \\
Lower secondary education & -0.115 & 0.227 & 0.051 & 0.232 \\
(Upper) secondary education & 0.326 & 0.186 & 0.185 & 0.189 \\
Post secondary non-tertiary education & 0.000 & - & 0.000 & - \\
Tertiary education & 0.109 & 0.248 & -0.156 & 0.300 \\
Married & 0.203 & 0.149 & 0.028 & 0.136 \\
Widowed & 0.440 & 0.163 & 0.421 & 0.167 \\
Divorced & 0.054 & 0.453 & -0.442 & 0.341 \\
Never married & -0.658 & 0.292 & -0.676 & 0.231 \\
Having a child & 0.000 & - & 0.000 & - \\
Intercept & 0.724 & 0.138 & 0.845 & 0.141 \\
\hline $\mathrm{N}$ & 10.524 & 0.454 & 9.766 & 0.468 \\
\hline R-squared & 655 & & 638 & \\
Adj R-squared & 0.115 & & 0.116 & \\
$\sigma_{\mu}$ & 0.101 & & 0.102 & \\
\hline
\end{tabular}

a The reference individual is a never married man (left) or woman (right), with (upper) secondary education and no children. 
when the father is in poor health and the mother has a good health status, the preference for informal care giving is lower. Presumably, mothers are better able to give informal care to their spouses than fathers are able to give informal care to the mothers of the adult children. Several studies find that mothers receive more care than fathers (Bonsang 2007; Klein Ikkink et al. 1999; Attias-Donfut et al. 2005). Our results suggest that this depends on the health status of the parent. Mothers in good health receive more informal care than fathers in good health, but fathers in bad health receive more informal care than mothers in good health (which is also as expected, if fathers in the generation under consideration indeed have lower homework skills). In addition to a bad health status, the preference for informal care increases with the age of the parent(s). This is in accordance with the literature, indicating that even after extensively controlling for disability, age remains an important driver of long term care use (De Meijer et al., 2009). The country specific dummy variables comprise institutional as well as cultural differences between countries. Institutional differences constitute for example publicly financed long term care programmes ${ }^{15}$ and the availability of formal care. Cultural differences include differences in social norms with regard to informal care and the degree to which family ties are considered to be important. It has been found that southern European countries have stronger family ties than northern European countries (Reher, 1998). The estimation results show that the preferences with regard to informal care are relatively high in Greece, Germany, Belgium, Austria, and Czechia. ${ }^{16}$ High educated children have significantly lower preferences for informal care than lower educated children. One argument in the literature is that higher educated children live farther away from their parents due to geographical labor market restrictions. However, also after taking into account distance we find a significant effect of education on the preference for informal care, which may be explained by different value orientations of the higher educated (Kalmijn, 2006) and/or competing interests (Waite and Harrison, 1992). ${ }^{17}$

\footnotetext{
${ }^{15}$ An overview of publicly financed long term care programmes can be found in Bolin et al. (2008b).

${ }^{16}$ It is remarkable that southern European countries like Italy and Spain do not have significantly positive results here. Probably this has to do with living arrangements. In Italy and Spain many adult care givers are co-residing with their parents and these households are not included in this analysis.

${ }^{17}$ Kalmijn (2006) found that face-to-face contact between higher educated children and their parents is relatively low, even after controlling for distance.
} 
Table 9: Estimation results structural model ${ }^{\mathrm{a}}$

\begin{tabular}{|c|c|c|c|c|}
\hline & & Coef. & Std. err. & $\mathrm{p}$-value \\
\hline$\alpha_{l l}$ & $\left(t_{l}^{2}\right)$ & -0.00018 & 0.00019 & 0.358 \\
\hline$\alpha_{c c}$ & $\left(c^{2}\right)$ & $1.44 \mathrm{e}-07$ & $2.38 \mathrm{e}-07$ & 0.546 \\
\hline$\alpha_{s s}$ & $\left(t_{s}^{2}\right)$ & -0.01226 & 0.00445 & 0.006 \\
\hline$\alpha_{l c}$ & $\left(t_{l} \times c\right)$ & 0.00002 & 0.00001 & 0.003 \\
\hline$\alpha_{l s}$ & $\left(t_{s} \times t_{l}\right)$ & 0.00230 & 0.00102 & 0.023 \\
\hline$\alpha_{c s}$ & $\left(t_{s} \times c\right)$ & $-1.43 \mathrm{e}-06$ & 0.00002 & 0.945 \\
\hline$\beta_{l 0}$ & $\left(t_{l}\right)$ & -0.25464 & 0.05971 & 0.000 \\
\hline$\beta_{l 1}$ & $\left(t_{l} \times\right.$ child is man $)$ & -0.10354 & 0.02051 & 0.000 \\
\hline$\beta_{l 2}$ & $\left(t_{l} \times\right.$ number children $)$ & 0.02203 & 0.00907 & 0.015 \\
\hline$\beta_{l 3}$ & $\left(t_{l} \times \operatorname{man} \times\right.$ number children $)$ & -0.03900 & 0.01133 & 0.001 \\
\hline$\beta_{l 4}$ & $\left(t_{l} \times\right.$ age child $)$ & 0.00564 & 0.00084 & 0.000 \\
\hline$\beta_{l 5}$ & $\left(t_{l} \times\right.$ child is married $)$ & 0.00757 & 0.01535 & 0.622 \\
\hline$\beta_{l 6}$ & $\left(t_{l} \times\right.$ child is divorced $)$ & -0.01272 & 0.02226 & 0.568 \\
\hline$\beta_{l 7}$ & $\left(t_{l} \times\right.$ child is widowed $)$ & 0.04751 & 0.04445 & 0.285 \\
\hline$\beta_{l 8}$ & $\left(t_{l} \times\right.$ child has low education level $)$ & 0.13144 & 0.03673 & 0.000 \\
\hline$\beta_{l 9}$ & $\left(t_{l} \times\right.$ child has high education level $)$ & -0.03662 & 0.01288 & 0.004 \\
\hline$\beta_{c 0}$ & $(c)$ & 0.02788 & 0.00410 & 0.000 \\
\hline$\beta_{c 1}$ & $\left(t_{c} \times\right.$ child is man $)$ & 0.00292 & 0.00161 & 0.070 \\
\hline$\beta_{c 2}$ & $\left(t_{c} \times\right.$ number children $)$ & -0.00096 & 0.00087 & 0.271 \\
\hline$\beta_{c 3}$ & $\left(t_{c} \times\right.$ man $\times$ number children $)$ & 0.00106 & 0.00092 & 0.249 \\
\hline$\beta_{c 4}$ & $\left(t_{c} \times\right.$ age child $)$ & -0.00050 & 0.00007 & 0.000 \\
\hline$\beta_{c 5}$ & $\left(t_{c} \times\right.$ child is married $)$ & 0.00348 & 0.00133 & 0.009 \\
\hline$\beta_{c 6}$ & $\left(t_{c} \times\right.$ child is divorced $)$ & 0.00355 & 0.00203 & 0.080 \\
\hline$\beta_{c 7}$ & $\left(t_{c} \times\right.$ child is widowed $)$ & 0.00235 & 0.00572 & 0.682 \\
\hline$\beta_{c 8}$ & $\left(t_{c} \times\right.$ child has low education level $)$ & 0.00288 & 0.00483 & 0.552 \\
\hline$\beta_{c 9}$ & $\left(t_{c} \times\right.$ child has high education level $)$ & 0.00320 & 0.00097 & 0.001 \\
\hline$\beta_{s 0}$ & $\left(t_{s}\right)$ & -3.03510 & 0.31385 & 0.000 \\
\hline$\beta_{s 1}$ & $\left(t_{s} \times\right.$ child is man $)$ & -0.23573 & 0.11326 & 0.037 \\
\hline$\beta_{s 2}$ & $\left(t_{s} \times\right.$ number children $)$ & 0.03988 & 0.04162 & 0.338 \\
\hline$\beta_{s 3}$ & $\left(t_{s} \times\right.$ man $\times$ number children $)$ & -0.11870 & 0.05818 & 0.041 \\
\hline$\beta_{s 4}$ & $\left(t_{s} \times\right.$ father good / very good health $)$ & -0.10545 & 0.18083 & 0.560 \\
\hline$\beta_{s 5}$ & $\left(t_{s} \times\right.$ father fair health $)$ & 0.88709 & 0.17274 & 0.000 \\
\hline$\beta_{s 6}$ & $\left(t_{s} \times\right.$ father poor health $)$ & 1.11773 & 0.20649 & 0.000 \\
\hline
\end{tabular}

a Table continues on the next page. 
Table 9: Estimation results structural model, continued $^{\mathrm{a}}$

\begin{tabular}{|c|c|c|c|c|}
\hline & & Coef. & Std. err. & p-value \\
\hline$\beta_{s 7}$ & $\left(t_{s} \times\right.$ mother good / very good health $)$ & 0.57372 & 0.15491 & 0.000 \\
\hline$\beta_{s 8}$ & $\left(t_{s} \times\right.$ mother fair health $)$ & 0.72741 & 0.14136 & 0.000 \\
\hline$\beta_{s 9}$ & $\left(t_{s} \times\right.$ mother poor health $)$ & 1.06507 & 0.16237 & 0.000 \\
\hline$\beta_{s 10}$ & $\left(t_{s} \times\right.$ both poor, or poor and fair health) & 1.01035 & 0.16383 & 0.000 \\
\hline$\beta_{s 11}$ & $\left(t_{s} \times\right.$ both fair, or fair and good health $)$ & 0.43515 & 0.13891 & 0.002 \\
\hline$\beta_{s 12}$ & $\left(t_{s} \times\right.$ father poor, mother good health $)$ & 0.67826 & 0.24108 & 0.005 \\
\hline$\beta_{s 13}$ & $\left(t_{s} \times\right.$ father good, mother poor health $)$ & 1.36701 & 0.22906 & 0.000 \\
\hline$\beta_{s 14}$ & $\left(t_{s} \times\right.$ Germany $)$ & 0.34698 & 0.12951 & 0.007 \\
\hline$\beta_{s 15}$ & $\left(t_{s} \times\right.$ Italy $)$ & -0.05540 & 0.14384 & 0.700 \\
\hline$\beta_{s 16}$ & $\left(t_{s} \times\right.$ Greece $)$ & 0.41713 & 0.12893 & 0.001 \\
\hline$\beta_{s 17}$ & $\left(t_{s} \times\right.$ Spain $)$ & 0.21706 & 0.14050 & 0.122 \\
\hline$\beta_{s 18}$ & $\left(t_{s} \times\right.$ France $)$ & 0.22165 & 0.12188 & 0.069 \\
\hline$\beta_{s 19}$ & $\left(t_{s} \times\right.$ Netherlands $)$ & -0.38264 & 0.18871 & 0.043 \\
\hline$\beta_{s 20}$ & $\left(t_{s} \times\right.$ Denmark $)$ & 0.18658 & 0.15070 & 0.216 \\
\hline$\beta_{s 21}$ & $\left(t_{s} \times\right.$ Belgium $)$ & 0.34925 & 0.12576 & 0.005 \\
\hline$\beta_{s 22}$ & $\left(t_{s} \times\right.$ Austria $)$ & 0.27338 & 0.13071 & 0.036 \\
\hline$\beta_{s 23}$ & $\left(t_{s} \times\right.$ Poland $)$ & -0.30224 & 0.18413 & 0.101 \\
\hline$\beta_{s 24}$ & $\left(t_{s} \times\right.$ Czechia $)$ & 0.59367 & 0.15322 & 0.000 \\
\hline$\beta_{s 25}$ & $\left(t_{s} \times(\right.$ average $)$ age parent -55$)$ & 0.03911 & 0.00492 & 0.000 \\
\hline$\beta_{s 26}$ & $\left(t_{s} \times\right.$ child has low education level $)$ & 0.36887 & 0.11600 & 0.001 \\
\hline$\beta_{s 27}$ & $\left(t_{s} \times\right.$ child has high education level $)$ & -0.25675 & 0.07192 & 0.000 \\
\hline$\sigma_{l}^{2}$ & & 0.02078 & 0.00442 & 0.000 \\
\hline$\sigma_{c}^{2}$ & & 0.00007 & 0.00001 & 0.000 \\
\hline$\sigma_{s}^{2}$ & & 1.02037 & 0.21353 & 0.000 \\
\hline$\sigma_{l c}$ & & -0.00121 & 0.00022 & 0.000 \\
\hline$\sigma_{l s}$ & & 0.02571 & 0.00853 & 0.003 \\
\hline$\sigma_{c s}$ & & -0.00148 & 0.00042 & 0.000 \\
\hline Log likelihood & & -2814.912 & & \\
\hline $\mathrm{N}$ & & 2253.000 & & \\
\hline
\end{tabular}

a The reference individual is a never married female adult child, of whom both parents are alive, have a good / very good health position, and are living in Sweden. 
Finally, we find that women have significantly higher preferences for providing informal care than men.

Secondly, we describe the parameter estimates related to leisure $\left(t_{l}\right)$. The preference for leisure increases with age and is somewhat lower for men than for women. Children increase women's preferences for leisure significantly, probably because more children often mean more responsibilities for adult daughters inside their own households (the care for a child also belongs to 'leisure time' in this model). Marital status does not affect adult children's preferences for leisure. Married persons spend leisure time with each other, but on the other hand household production is more efficient for couples than for singles, which saves time. ${ }^{18}$ Finally, low educated children have significantly higher preferences for leisure, and high educated children have significantly lower preferences for leisure. Maybe, less favorable labor conditions among the lower educated bring about higher preferences for leisure time rather than labor time.

The parameter estimates related to consumption $(c)$ show that older children have significantly lower preferences for consumption. In addition, married persons and higher educated individuals have a relatively high preference for consumption. As mentioned before, for the model to be economically rational, the marginal utility of consumption must be positive. We find that for all but 18 observations $(0.8 \%)$ this condition holds. These 18 adult children have a high age, which leads to a relatively low preference for consumption in the model (as can be seen from the coefficient $\beta_{c 4}$ ).

The final part of table 9 shows the estimates of the covariance matrix of the unobserved heterogeneity terms (equation 4), which are in line with our expectations. All coefficients are significant, indicating that unobserved heterogeneity is important. The negative sign of $\sigma_{l c}$ indicates that unobserved characteristics which increase the preference for leisure tend to have a negative effect on the preference for consumption. In the same way, the negative value for $\sigma_{c s}$ indicates that unobserved characteristics which increase the preference for informal care, have in general a negative effect on the preference for consumption. Finally, $\sigma_{l s}$ shows that if persons have a relatively high preference for leisure (conditional on the observed characteristics in the model), they also have on average a somewhat higher preference for informal care.

The relations between wage rates, distances, and informal care follow from the estimated preference parameters and the time and budget constraint. To facilitate interpretation of the results, figure 1 shows the relation between geographical distance and the amount of informal

\footnotetext{
${ }^{18}$ Waite and Harrison (1992) found that the presence of a husband decreases the number of visits a woman has with friends, but does not reduce a woman's social contacts with kin.
} 
care given by a reference individual in the model. As a reference individual we consider a married German women of age 55, with an 80 year old father in poor health, no mother, and 2 children of her own. She has a medium education level, a wage rate of 10 euros per hour and her remaining household income is 15,000 euros per year. Unobserved heterogeneity is important regarding the preferences for informal care. Figure 1 therefore shows seven lines. Each line represents the reference individual with a different random effect $u_{s}$. These reflect, for example, different levels of family ties, degree of altruism, or feelings of obligation to provide informal care. The line 'p50' shows the relationship between distance and informal care when all random effects $u_{l}, u_{c}$ and $u_{s}$ are equal to zero. This means that the unobserved preferences with regard to leisure, consumption, and informal care are at the median level. For example, with regard to informal care we can interpret this reference individual to have 'median responsibility norms'. The line 'p90' represents the reference individual with high unobserved preferences for informal care. Only $10 \%$ of the individuals have a higher random effect $u_{s}$. The same explanation holds for the other lines, p10, p25, p60, p70, and p80. For example, for line p25, only $25 \%$ of the people have smaller unobserved preferences for informal care. $u_{l}$ and $u_{c}$ are zero for all lines, such that the only difference between the lines is the random effect $u_{s}$, the unobserved heterogeneity with regard to informal care.

Figure 1: Estimated relationship between distance and the expected supply of informal care to elderly parents for the reference individual

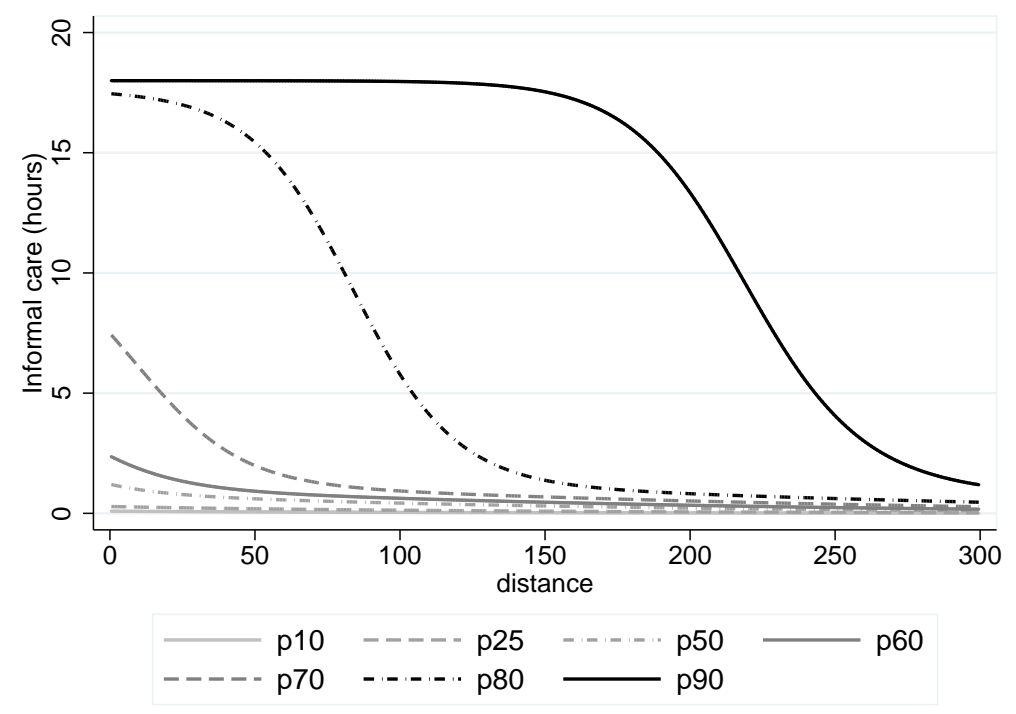

Figure 1 shows that the reference person with 'median' unobserved preferences for informal care provides almost no informal care. This is as expected, since we found in table 3 that only 
$34 \%$ of the only children with a father in bad health provide informal care. The higher the preference of the reference individual to provide care, the longer it takes before informal care decreases with distance (distance elasticity is low for persons with high preferences for informal care).

The distance between adult children and their parents may also influence the labor force participation of the adult children. Unsurprisingly, figure 2 presents that for the majority of the adult children, who give almost no informal care, distance does not influence labor force participation. Focussing on p70, we see that labor supply increases with distance. Apparently, at least part of the reduction in informal care is replaced by labor. For those with relatively high preferences for informal care, labor force participation first declines when distance increases, as more travel time is needed for the provision of informal care. However, after a certain distance (e.g. 50 kilometers for the 80th percentile), informal care decreases and labor force participation increases.

Figure 2: Estimated relationship between distance and the expected supply of labor

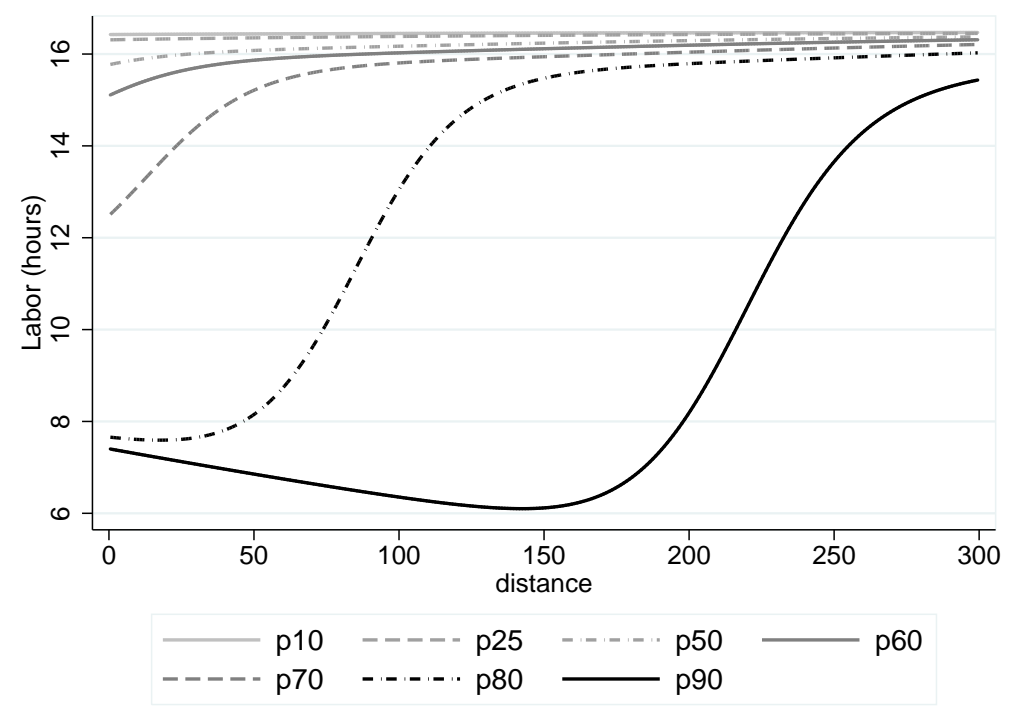

Figure 3 and 4 show the relation between the wage rate of the reference individual, the expected number of hours of participation in the labor market, and the hours of informal care the reference individual provides to her father. In these figures the distance between the reference individual and her father is 7.5 kilometers. The seven lines represent different levels of the unobserved heterogeneity term with regard to informal care, just as explained for figure 1. In line with the literature (e.g. Evers et al., 2008), figure 3 shows a positive wage elasticity of labor supply. Reference individuals with higher preferences for informal care are less active in 
the labor market. For example, at the wage rate of 10 euros per hour, the reference individual with a high preference for informal care (p90) participates about 9 hours less on the labor market than the reference individual with a low unobserved preference for informal care (p10).

Figure 3: Relationship between wages and the expected hours of labor supply for the reference individual

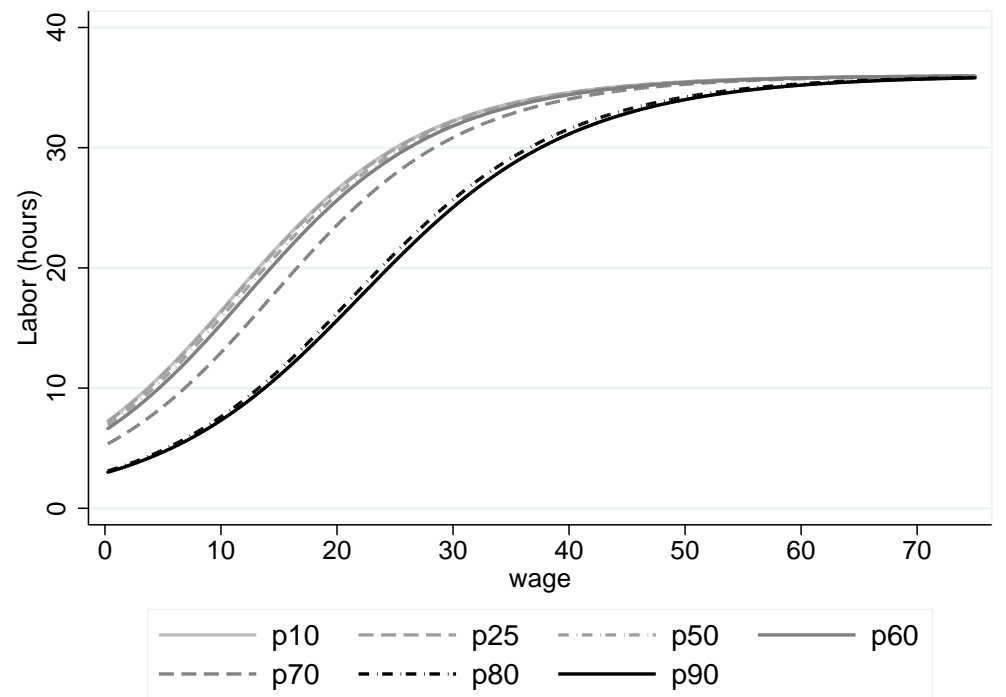

Figure 4: Relationship between wages and the expected supply of informal care to elderly parents for the reference individual

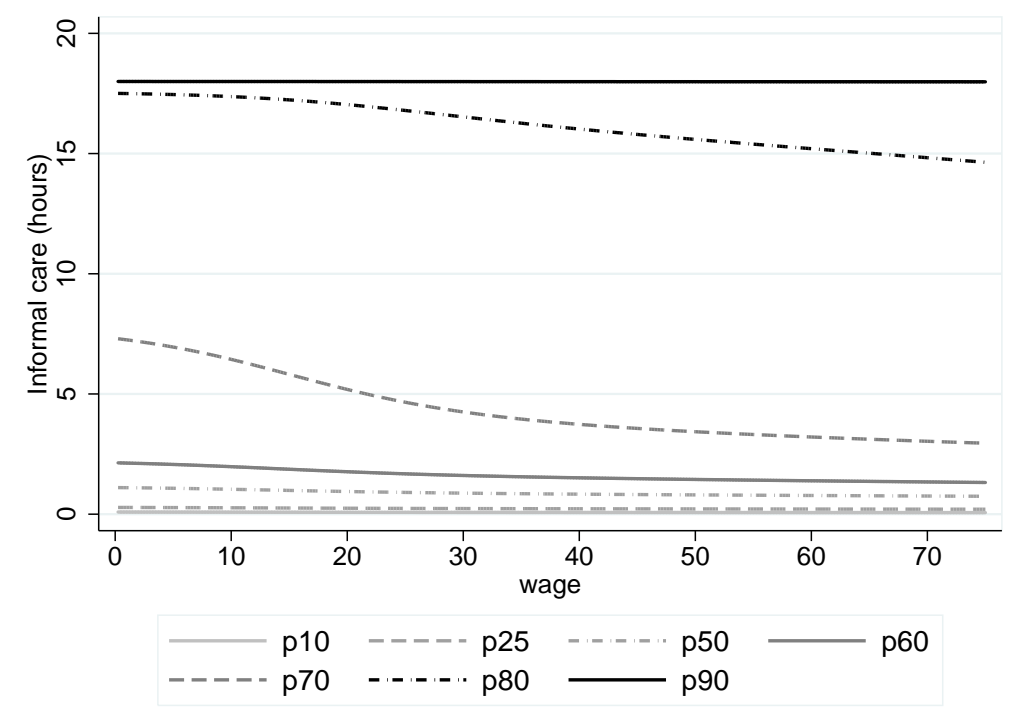

According to Figure 4 the wage elasticity of informal care supply is small. The wage elasticity for a reference individual with large norms of responsibility (or other reasons that lead to a high 
unobserved preference for informal care) is almost zero.

\section{Two adult children}

In families with two siblings, informal care provision to parents is determined by the characteristics of both siblings, and the nature of the interaction between siblings. In this section we use the estimates of the structural model, estimated for only children, to families with two adult children. When applying the estimates of only children to siblings, some assumptions are required. First of all, we assume that siblings have the same preferences for leisure, consumption and informal care as only children. Regarding informal care, this assumption is in line with Spitze and Logan (1991), who found that children's closeness to parents and attitudes towards filial responsibility is unrelated with being an only child or not. According to their study, differences in support between families with different numbers of siblings are not attributable to different attitudes or feelings of closeness between these families. Instead, to explain differences in support between families of different size, they propose that attention should be paid on how each child adjusts his or her own behavior when more children are potentially available for contact and support to parents (which corresponds to our assumption). The only difference between only children and siblings in our model is that in families with two adult children there is now a sibling available who can also provide informal care (the hours of informal care $t_{s}$ in the utility function becomes the sum of own informal care and informal care provided by the sibling). We assume that own informal care and informal care provided by the sibling are perfect substitutes. This means that children receive the same direct utility from an hour of informal care provided by themselves or by their sibling (this utility is $\beta_{s}$, from equation 3 ). Also, an hour of informal care provided by one of the siblings decreases the marginal utility of an extra hour of informal care by $\alpha_{s s}$ (the same as in the model for only children), it increases the utility obtained from leisure by $\alpha_{l s}$, and it changes the marginal utility of consumption by $\alpha_{c s}$ (not significant). Only, for those siblings with a negative direct utility from informal care $\left(\beta_{s}<0\right)$, we assume that they do not receive any direct utility from an extra hour of informal care provided by their sibling (these are, for example, individuals with healthy parents and/or low unobserved preferences for informal care). Finally, we assume that both siblings have their own time and budget constraints and that there are no financial transfers between siblings. The amount of informal care provided may be the outcome of a noncooperative or cooperative game between two siblings. 
Section 6.1 describes how we derive noncooperative and cooperative equilibria. Next, we show some simulations of cooperative and noncooperative behavior between reference siblings (6.2). Finally, we apply the model estimated in this study to the families with two siblings in SHARE, to get an indication whether siblings behave cooperatively or noncooperatively, and to estimate the expected gains from cooperation between siblings (6.3).

\subsection{Cooperative and noncooperative equilibria}

\subsubsection{Noncooperative equilibrium}

In the noncooperative equilibrium, we assume that both siblings maximize their utility, given the choice of their sibling and their own time and budget constraint. We use a generalization of the Nash equilibrium, based on the assumption that a player's rationality is bounded. Bounded rationality is incorporated by adding random disturbance to the payoffs of the players, just as we did for only children in (5). Just as for only children, we assume that siblings are more likely to choose better strategies than worse strategies, but do not play a best strategy with probability one (children are "better responders" rather than "best responders"). This concept, in a gametheoretic framework, has been explained by McKelvey and Palfrey $(1995,1998)$ and is called the Quantal Response Equilibrium (QRE). As we add random errors distributed according to the type I extreme value distribution, we have a special version of the Quantal Response Equilibrium, namely the logit equilibrium (LQRE, Anderson et al., 2002). The LQRE extends the model we estimated for only children to the situation with two or more siblings. In the logit equilibrium the sibling's alternatives are chosen according to the probability distribution

$$
p_{i, m}=\frac{\exp \left(\lambda E\left(U\left(t_{i, m} \mid p_{j}\right)\right)\right.}{\sum_{k=1}^{12} \exp \left(\lambda E\left(U\left(t_{i, k} \mid p_{j}\right)\right)\right.} \quad m=1, \ldots, 12
$$

where $p_{i m}$ is the probability of sibling $i$ choosing alternative $m$. $E\left(U\left(t_{i, m} \mid p_{j}\right)\right)$ is the expected utility to player $i$ of choosing alternative $m$ when sibling $j$ has probability distribution $p_{j}$ for the 12 alternatives. The time and budget constraints are substituted in the utility function. The nonnegative parameter $\lambda$ is inversely related to the level of error and can be interpreted to reflect the degree of bounded rationality. When $\lambda \rightarrow \infty$, players become 'perfectly rational' and the logit equilibrium converges to the Nash equilibrium. In the other extreme case, when $\lambda=0$, the probabilities of the twelve alternatives converge to $1 / 12$, for both siblings (i.e., siblings make extremely noisy choices). Unfortunately, the error parameter $\lambda$ can not be identified (Haile et al., 2008). Standard multinomial logit models assume $\lambda=1$ and consistent with the model 
for only children, we also assume $\lambda=1 .^{19}$

The logit response functions $p_{i}$ and $p_{j}$ are functions of each other. For example, the probability of sibling 1 choosing alternative $m$ depends on the probabilities of sibling 2 choosing the alternatives 1 to 12 . On the other hand, the probability of sibling 2 choosing alternative $m$ depends on the probabilities of sibling 1 choosing the alternatives 1 to 12 . We find the logit equilibrium by solving the logit response functions, which form a system of 24 nonlinear equations that are listed in Appendix 6.2.

\subsubsection{Cooperative equilibrium}

In the cooperative equilibrium, we assume siblings to maximize the sum of their utilities.

$$
U\left(t_{1}, t_{2}\right)=\gamma U\left(t_{1}\right)+(1-\gamma) U\left(t_{2}\right) \quad \gamma \in[0,1]
$$

subject to their own time and budget constraints. We choose $\gamma=0.5$, which is one choice out of the large set of Pareto solutions. ${ }^{20}$

For each of the $12 \times 12=144$ possible alternatives for the two siblings we compute $U\left(t_{1}, t_{2}\right)$, and we use these utilities to compute the probability of each alternative in the same way as we did for only children (equation 6). The probability of alternative $l$ is

$$
q_{l}=\frac{\exp \left(U\left(t_{1, l}, t_{2, l}\right)\right)}{\sum_{k=1}^{144} \exp \left(U\left(t_{1, k}, t_{2, k}\right)\right)} \quad l=1, \ldots, 144
$$

\subsection{Simulations}

In this section we simulate some noncooperative and cooperative equilibria. For these simulations we stick to our reference person, specified in section 5.2 (a woman of age 55, who is married and living in Germany, she has a 80 year old father in poor health, no mother, two children, a medium education level, a remaining household income of 15,000 euros per year, and a wage rate of 10 euros per hour). However, in this section our reference person is no only child anymore. First, we assume that she has a sister, who has exactly the same characteristics as herself. This sister lives 7.5 kilometers from the parent. The first figure of 5 presents the

\footnotetext{
${ }^{19}$ For future research it may be interesting to allow $\lambda$ to vary with the education levels of the adult children.

${ }^{20}$ In section 6.3 we do a sensitivity analysis, which shows that the conclusions are not very sensitive to the choice of the weights. The small differences can be explained by the fact that characteristics of siblings are often about the same. The health status and country of living of the parents are naturally the same for both siblings. Also, in $61.23 \%$ of the families the education level of the siblings is the same, and in $46 \%$ of the families the gender of the siblings are the same.
} 
Figure 5: Cooperative and noncooperative outcomes for two siblings, by distance of the reference individual
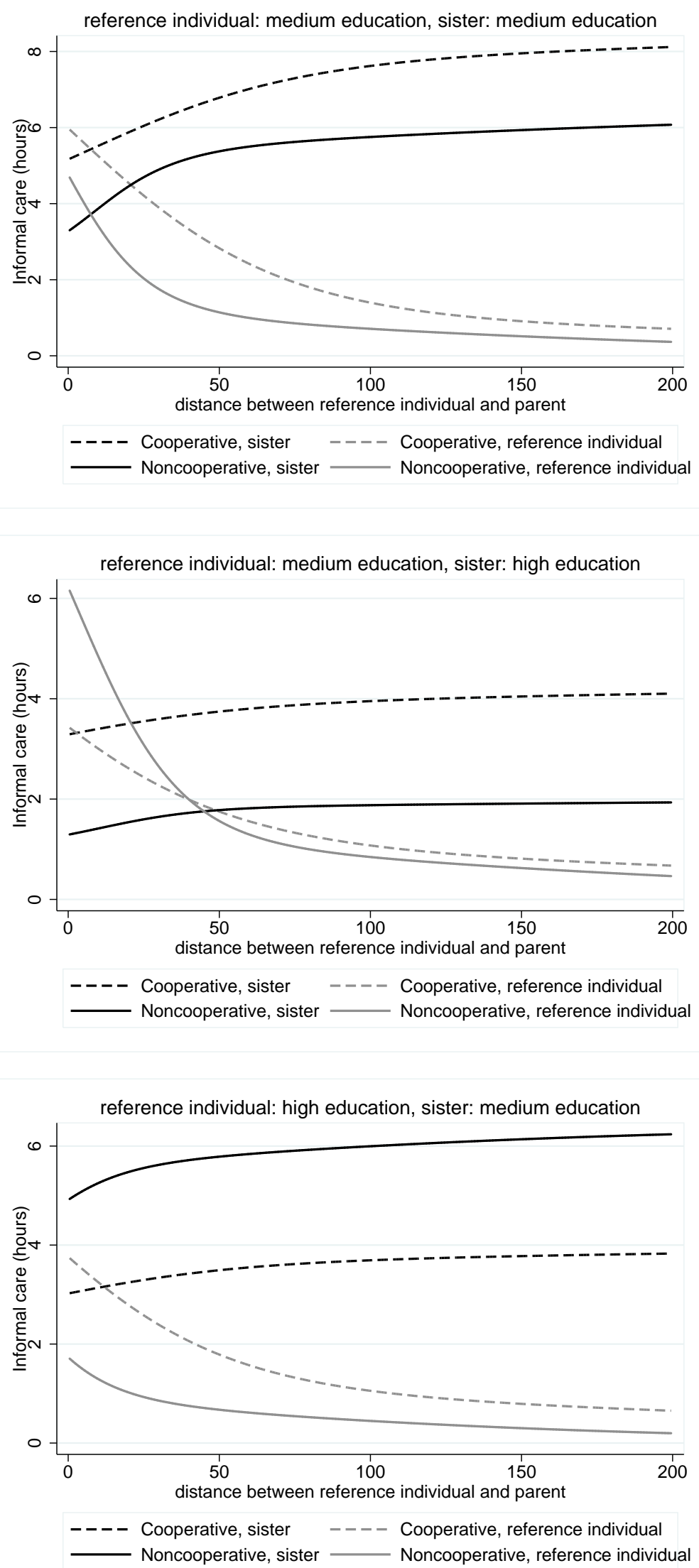
amount of care that these two sisters are providing to their parent, for different geographical distances of our reference individual. ${ }^{21}$ At the distance of 7.5 kilometers, both siblings have exactly the same characteristics, and we see that they indeed give the same amount of care.

When the distance of our reference individual to the parent increases, the amount of care provided by our reference sibling decreases, but the amount of care provided by her sister increases (she compensates part of the loss of informal care). The total amount of informal care provided is higher in the cooperative equilibria than in the noncooperative equilibria. Compared to the situation where our reference person was an only child (p70 in figure 1), in the noncooperative equilibria our reference person provides substantial less informal care.

In the second figure of 5 the sister of our reference person, explained above, has a high education level instead of a medium education level (the two sisters still have the same wage rate). In the presence of the high educated sister, our reference person provides more informal care in the noncooperative equilibria than in the cooperative equilibria (until about 40 kilometers), because she has a higher preference for informal care than her sister. When the reference individual lives farther from their father, her high educated sister increases her provision of informal care slightly.

When we switch the education levels for our reference person and her sister (such that the reference person has a high education level and her sister has a medium education level), we find the equilibria shown in the third figure of 5 . In the noncooperative equilibria the medium educated sister provides most of the informal care, whereas in the cooperative equilibria informal care is more shared between the reference individual and her sisters.

\subsection{Interactions between siblings in SHARE}

The simulations in the previous section showed us that the nature of the interactions between children can have a large effect on the division of informal care between siblings and the total amount of informal care provided to parents. In this section we apply the estimated structural model to families with two adult children in SHARE (described in section 4). First, we examine the fit of cooperative and noncooperative equilibria. Second, we investigate which siblings behave cooperatively and noncooperatively (using observed characteristics). Finally, we study

\footnotetext{
${ }^{21}$ In section 5.2 we found that only those who have a relatively high unobserved random effect for informal care provide informal care. In figure 5 we therefore assume the sisters to have unobserved preferences for informal care at the 70th percentile, corresponding to the line 'p70' in section 5 (30\% of the of the adult children have a higher random effect $u_{s}$ ).
} 
the gains that can be achieved by cooperation.

To examine the fit of cooperative and noncooperative equilibria we predict the cooperative and noncooperative outcomes for the siblings in SHARE (using their observed characteristics and the structural parameter estimates from the only child empirical results), and compare them with their realized outcomes. Cooperative and noncooperative equilibria are described by probabilities for each of the twelve alternatives described in section 3 , for both siblings. We examine the fit of the cooperative and noncooperative equilibria by the sum (over siblings) of the probabilities for the realized options, divided by the number of siblings. This can be interpreted as the percentage of correct predictions of the model. The noncooperative model has a higher fit than the cooperative model (26.8\% versus $17.3 \%)$. In the noncooperative model siblings provide on average 1.13 hours of informal care per week, whereas in the cooperative model this is 1.63 hours. The realized average hours of informal care is also closer to the noncooperative outcome than to the cooperative outcome, namely 1.18 hours per week.

The next question we want to answer is which people tend to behave cooperatively and which people tend to behave noncooperatively. We measure the degree of noncooperativeness by the difference between the noncooperative and the cooperative predicted probabilities for the realized outcome. Figure 6 shows the histogram of this measure of noncooperativeness and can be interpreted as follows: when the degree of noncooperativeness is 0.1 , the predicted probability for the observed outcome is $10 \%$-points higher in the noncooperative model, compared to the cooperative model. The histogram shows that for most of the families $(71 \%)$ the predicted probability for the observed outcome is higher in the noncooperative model than in the cooperative model (the noncooperative model has a better fit). Even, for $47 \%$ of the families the predicted probability for the observed outcome is more than $10 \%$-points higher in the noncooperative model than in the cooperative model. ${ }^{22}$ The spike around zero includes families for whom the cooperative and the noncooperative outcome are about the same.

\footnotetext{
${ }^{22} \mathrm{~A}$ sensitivity analysis shows that the conclusions are not very sensitive to the weights chosen in equation (20). For example, when we choose the weights to be 0.3 and 0.7 (instead of 0.5 and 0.5 ) the fit of the cooperative model is $14.6 \%$ instead of $17.3 \%$, the number of hours of informal care is 1.81 instead of $1.63,75 \%$ of the families have a better fit for the noncooperative equilibrium (instead of $71 \%$ ), and for $50 \%$ of the families the predicted probability for the observed outcome is more than 10\%-points higher in the noncooperative model than in the cooperative model (instead of $47 \%$ when the weights are 0.5 and 0.5 ).
} 
Figure 6: Histogram degree of noncooperativeness

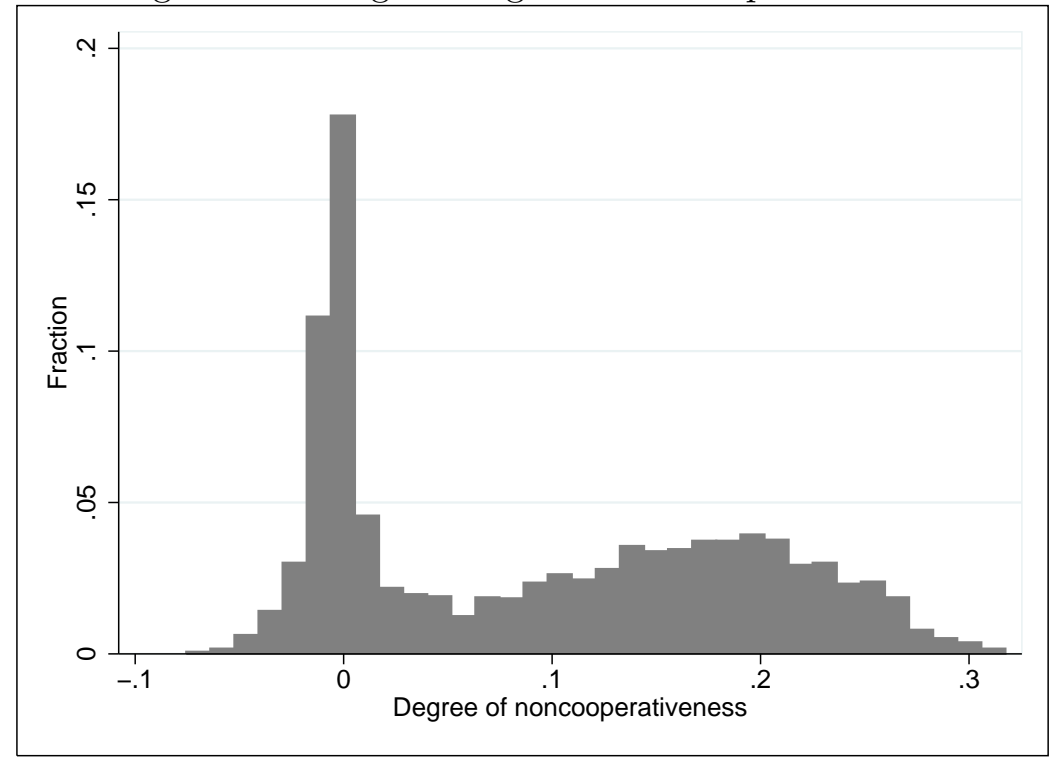

We regress the degree of noncooperativeness on several background characteristics of the siblings. The results in table 10 show that, relative to two sisters, the noncooperativeness of two brothers is on average 10.5\%-points higher (a 10.5\%-points higher difference between the predicted probabilities of the observed outcomes for the noncooperative and the cooperative model). Also, a brother-sister relationship appears to be more cooperative than a brotherbrother relationship. This may be explained by the fact that traditionally women are kin keepers. It has been found that sister-to-sister relationships and sister-to-brother relationships show on average greater emotional closeness and more frequency of contact than brother-brother relationships (Connidis and Campbell, 1995). Furthermore, when both of the siblings have a high education level, or when one of them has a high education level and the other a medium education level, they are significant less cooperative than two medium or low educated siblings. On average, relative to two low educated siblings, the noncooperativeness of two high educated siblings is $3.2 \%$-points higher. Finally, older siblings and siblings with a larger age difference have a significantly higher probability to behave cooperatively, and the differences in cooperativeness between countries is small. Siblings in Austria and the Netherlands behave slightly more cooperatively than siblings in Sweden, while siblings in Spain, Italy and Denmark behave somewhat less cooperatively. In the results of table 10 the degree of noncooperativeness and the preferences for informal care are separated by the assumption that differences in behavior between children with and without siblings are due to dissimilar constraints only. For example, table 10 shows that women are more cooperative than men, where we already take into account 
that women also have higher preferences for informal care than men (table 9). Also, for example, wage rates are taken into account in the structural model, such that higher opportunity costs resulting from higher wage rates of men can not explain the higher degree of noncooperativeness of men compared to women.

To obtain insights in the gains that can be achieved from cooperation, we compute the increase in the hours of informal care that would occur when those who seem to be noncooperative would change to cooperative behavior. When those who tend to be noncooperative (they have a higher probability to be noncooperative than to be cooperative) could be pushed into cooperative behavior, their average provision of informal care would increase from 1.04 hours per week to 1.52 hours per week. So, their parents would on average receive 0.96 hours of informal care per week more from their children, which is a growth of $46.2 \%$. While informal care increases when families are pushed into their cooperative outcome, the number of persons working full-time in the labor market decreases with 5.7\%-points and the number of persons working part-time increases with $6.7 \%$-points. 


\begin{tabular}{|c|c|c|c|}
\hline & Coef. & Std. err. & $\mathrm{p}$-value \\
\hline \multicolumn{4}{|l|}{ Gender } \\
\hline 2 sisters & 0.000 & - & - \\
\hline brother and sister & 0.020 & 0.004 & 0.00 \\
\hline 2 brothers & 0.105 & 0.005 & 0.00 \\
\hline \multicolumn{4}{|l|}{ Age } \\
\hline Age youngest sibling & -0.004 & 0.000 & 0.00 \\
\hline Age difference between the siblings & -0.002 & 0.001 & 0.00 \\
\hline \multicolumn{4}{|l|}{ Education } \\
\hline Both low education level & -0.014 & 0.010 & 0.17 \\
\hline Both high education level & 0.032 & 0.004 & 0.00 \\
\hline low and medium education level & -0.018 & 0.008 & 0.02 \\
\hline low and high education level & -0.006 & 0.015 & 0.67 \\
\hline medium and high education level & 0.021 & 0.004 & 0.00 \\
\hline \multicolumn{4}{|l|}{ Number of children } \\
\hline Minimum number of children of both siblings & -0.004 & 0.002 & 0.07 \\
\hline Difference in number of children between siblings & 0.000 & 0.002 & 0.91 \\
\hline \multicolumn{4}{|l|}{ Partners } \\
\hline No partners & 0.000 & - & - \\
\hline One sibling has partner & -0.004 & 0.009 & 0.63 \\
\hline Both siblings have a partner & -0.006 & 0.009 & 0.53 \\
\hline \multicolumn{4}{|l|}{ Country of the parents } \\
\hline Sweden & 0.000 & - & - \\
\hline Austria & -0.016 & 0.007 & 0.04 \\
\hline Belgium & 0.001 & 0.007 & 0.85 \\
\hline Germany & -0.012 & 0.007 & 0.08 \\
\hline Denmark & 0.019 & 0.007 & 0.01 \\
\hline Spain & 0.031 & 0.008 & 0.00 \\
\hline France & 0.004 & 0.007 & 0.54 \\
\hline Italy & 0.030 & 0.008 & 0.00 \\
\hline The Netherlands & -0.019 & 0.007 & 0.01 \\
\hline Czechia & -0.011 & 0.007 & 0.12 \\
\hline Greece & -0.005 & 0.006 & 0.45 \\
\hline Poland & 0.013 & 0.010 & 0.16 \\
\hline Constant & 0.238 & 0.017 & 0.00 \\
\hline $\mathrm{N}$ & 2891 & & \\
\hline $\mathrm{R}^{2}$ & 0.251 & & \\
\hline
\end{tabular}




\section{Conclusions}

This study presents a structural model to analyze families' complex decisions regarding informal care provision for aging parents. In the model adult children maximize their utility, defined over consumption, leisure, and the amount of care that parents receive from their children, subject to a time and budget constraint.

In the first part of this paper the preference parameters of the model are estimated using only children, such that interactions between siblings do not play a role. The results show that the preference for informal care is influenced by the health of the parents, the gender and education level of the adult children, and cultural and institutional differences between countries. Also unobserved individual specific preferences such as altruism, reciprocity and responsibility norms play a large role in the preferences of adult children to give informal care. The (negative) wage elasticity of informal care supply appears to be small.

The second part of the paper focuses on the strategic interactions between siblings. In the literature is has been emphasized that modeling family decisions as a bargaining process is important to increase our understanding of these decisions. An important follow-up question is whether this bargaining process is cooperative or noncooperative. In a structural model with two siblings one has to make assumptions about the nature of the interactions between siblings. When part of the siblings are cooperative and another part is noncooperative, this cannot be identified in general together with the other coefficients in a game-theoretic model. In some way, one needs information about the (non)cooperativeness of siblings, which is often not available. Most often, empirical game-theoretic models assume that siblings make noncooperative decisions. This study aims to establish the nature of the interactions between siblings using the structural parameter estimates of only children. We show that the nature of the interactions between siblings can have a large effect on the division of informal care between siblings and the total amount of informal care provided to parents. Furthermore, it appears that for $71 \%$ of the siblings the noncooperative model has a better fit than the cooperative model (which means that the assumption of noncooperative siblings used by current game-theoretic models is most likely for the majority of the siblings). The degree of cooperativeness varies most with the gender of the siblings. The fit of the noncooperative model compared to the cooperative model is $10.5 \%$-points higher for two brothers relatively to two sisters.

Furthermore, two high educated siblings or a high and medium educated sibling appear to be less cooperative on average than two medium or low educated siblings, and older siblings 
have a significant higher probability to behave cooperative.

For future research it may be interesting to estimate this model using U.S. data from the Health and Retirement Study (HRS). The HRS has the advantage that it also contains information about family income of the adult children.

For policy design we can conclude that a reduction in the geographical distance between adult children and their parents would be an effective measure to increase informal care as well as the labor force participation of those children with a relatively high preference for informal care. For example, the social rent sector could weigh informal care in their assignment of houses, or senior houses could be built in residential areas. For fiscal policies it may be of interest that net wages have negligible effects on the provision of informal care, while they do influence labor supply. Pushing noncooperative families into their cooperative equilibria would increase the provision of informal care, but this would be at the expense of the labor supply of adult children. 


\section{References}

Anderson, S., Goeree, J., Holt, C., 2002. The logit equilibrium: a perspective on intuitive behavioral anomalies. Southern Economic Journal 69 (1), 21-47.

Attias-Donfut, C., Ogg, J., Wolff, F., 2005. Health, Ageing and Retirement in Europe - First Results from the Survey of Health, Ageing and Retirement in Europe. Mannheim: MEA, Ch. Financial transfers, pp. 179-185.

Bell, D., Dowes, A., Heitmueller, A., 2006. Did the introduction of free personal care in scotland result in a reduction of informal care?, paper presented at IZA conference on the Well-Being of the Elderly.

Bernheim, B.D., S. A., Summers, L., 1985. The strategic bequest motive. Journal of Political Economy 93, 1045-1076.

Bolin, K., Lindgren, B., Lundborg, P., 2008a. Informal and formal care among single-living elderly in europe. Health Economics 17 (3), 393-409.

Bolin, K., Lindgren, B., Lundborg, P., 2008b. Your next of kin or your own career? caring and working among the 50+ of europe. Journal of Health Economics 27 (3), 718-738.

Bonsang, E., 2007. How do middle-aged children allocate time and money transfers to their older parents in europe? Empirica 34, 171-188.

Bonsang, E., 2009. Does informal care from children to their elerly parents substitute for formal care in europe. Journal of Health Economics 28, 143-154.

Byrne, D., Goeree, M., Hiedemann, B., Stern, S., 2009. Formal home health care, informal care, and family decision making. International Economic Review 50 (4), 1205-1242.

Callegaro, L., Pasini, G., 2008. Social interaction effects in an inter-generational model of informal care giving, Netspar Discussion Paper 2008-023.

Charles, K., Sevak, P., November 2005. Can family caregiving substitute for nursing home care. Journal of Health economics 24 (6), 1174-1190.

Checkovich, T., Stern, S., 2002. Shared caregiving responsibilities of adult siblings with elderly parents. The Journal of Human Resources 37 (3), 441-478. 
Connidis, I., Campbell, L., 1995. Closeness, confiding, and contact among siblings in middle and late adulthood. Journal of Family Issues 16 (6), 722-745.

Crespo, L., Mira, P., 2010. Caregiving of elderly parents and employment status of european mature women, working paper presented at the Econometric Society World Congress.

De Meijer, C., Koopmanschap, M., Koolman, X., Van Doorslaer, E., 2009. The role of disability in explaining long-term care utilization. Medical Care 47 (11), 1156-1163.

Drukker, D., Gates, R., 2006. Generating halton sequences using mata. The Stata Journal 6 (2), $214-228$.

Dykstra, P., 1993. The differential availability of relationships and the provision and effectiveness of support to older adults. Journal of Social and Personal Relationships 10, 355-370.

Eggebeen, D., Hogan, D., 1990. Giving between generations in american families. Human Nature $1,211-232$.

Engers, M., Stern, S., 2002. Long-term care and family bargaining. International Economic Review 43 (1), 73-114.

Ettner, S., 1995. The impact of 'parent care' on female labor supply decisions. Demography $32(1), 63-80$.

Ettner, S., 1996. The opportunity cost of elder care. The Journal of Human Resources 31 (1), 189-205.

Evers, M., De Mooij, R., Van Vuuren, D., 2008. The wage elasticity of labour supply: A synthesis of empirical estimates. De Economist 156 (1), 25-43.

Fontaine, R., Gramain, A., Wittwer, J., 2009. Providing care for an elderly parent: interactions among siblings. Health economics 18 (9), 1011-1029.

Frankenberg, E., Lillard, L., Willis, R., 2002. Patterns of intergenerational transfers in southeast asia. Journal of Marriage and the Family 64, 627-641.

Grundy, E., 2005. Reciprocity in relationships: Socio-economic and health influences on intergenerational exchanges between third age parents and their adult children in great britain. British Journal of Sociology 56, 233-255. 
Haile, P., Hortacsu, A., Kosenok, G., 2008. On the empirical content of Quantal Response Equilibrium. American Economic Review 98 (1), 180-200.

Heckman, J., 1979. Sample selection bias as a specification error. Econometrica 47 (1), 153-161.

Hiedemann, B., Stern, S., 1999. Strategic play among family members when making long-term care decisions. Journal of economic behavior and organization 40, 29-57.

Hoerger, T., Picone, G., Sloan, F., 1996. Public subsidies, private provision of care and living arrangements of the elderly. Review of Economics and Statistics 78 (3), 428-440.

Hogan, D., Eggebeen, D., 1995. Sources of emergency help and routine assistance in old-age. Social Forces 73, 917-936.

Kalmijn, M., 2006. Educational inequality and family relationships: Influences on contact and proximity. European Sociological Review 22, 1-16.

Kalmijn, M., 2007. Gender differences in the effects of divorce, widowhood, and remarriage on intergenerational support: Does marriage protect fathers? Social Forces 85 (3), 1079-1104.

Kalmijn, M., 2010. Verklaring van intergenerationele solidariteit: een overzicht van concurrerende theorieën en hun ondezoeksbevindingen. Mens en Maatschappij 85 (1), 70-98.

Kalmijn, M., Dykstra, P., 2006. Family solidarity in the Netherlands. Amsterdam: Dutch University Press, Ch. Differentials in face-to-face contact between parents and their grown-up children, pp. 63-88.

Kalmijn, M., Saraceno, C., 2008. A comparative perspective on intergenerational support: Responsiveness to parental needs in individualistic and familialistic countries. European Societies $10(3), 479-508$.

Klein Ikkink, K., Van Tilburg, T., Knipscheer, K., 1999. Perceived instrumental support exchanges in relationships between elderly parents and their adult children: Normative and structural explanations. Journal of Marriage and the Family 4, 831-844.

Kohli, M., 1999. Private and public transfers between generations: Linking the family and the state. European Societies 1, 81-104.

Kohli, M., Künemund, H., 2003. Families, aging and social supports: International perspectives. Hawthorne, New York: Aldine De Gruyter, Ch. Intergenerational transfers in the family: what motives giving, pp. 123-142. 
Kotlikoff, L., Morris, J., 1990. Why don't the elderly live with their children? A new look. University of Chicago Press, Chicago, Ch. 5, pp. 149-172.

Lee, Y., Parish, W., Willis, R., 1994. Sons, daughters, and intergenerational support in taiwan. American Journal of Sociology 99, 1010-1041.

McGarry, K., September 1999. Inter vivos transfers and intended bequests. Journal of Public Economics 73 (3), 321-351.

McKelvey, R., Palfrey, T., 1995. Quantal response equilibria for normal form games. Games and Economic Behavior 10, 6-38.

McKelvey, R., Palfrey, T., 1998. Quantal response equilibria for extensive form games. Experimental Economics 1, 9-41.

Norton, C., Van Houtven, C., July 2006. Inter-vivos transfers and exchange. Southern Economic Journal 73 (1), 157-172.

Perozek, M., 1998. A reexamination of the strategic bequest motive. Journal of Political Economy $106(2), 423-445$.

Pezzin, L., Schone, B., 1997. The allocation of resources in intergenerational households: Adult children and their elderly parents. American Economic Review 87 (2), 440-464.

Pezzin, L., Schone, B., 1999. Intergenerational household formation, female labor supply and informal caregiving: A bargaining approach. The Journal of Human Resources 34 (3), 475503.

Reher, D., 1998. Family ties in western europe. Population and development review 24, 203-234.

Silverstein, M., 1995. Stability and change in temporal distance between the elderly and their children. Demography 32, 29-46.

Silverstein, M., Bengtson, V., 1997. Intergenerational solidarity and the structure of adult childparent relationships in american families. American Journal of Sociology 103, 429-460.

Sloan, F., Picone, G., Hoerger, J., 1997. The supply of children's time to disabled elderly parents. Economic Inquiry 35 (2), 295-308.

Spitze, G., Logan, J., 1989. Gender differences in family support: Is there a payoff? The Gerontologist 29, 108-113. 
Spitze, G., Logan, J., 1991. Sibling structure and intergenerational relations. Journal of Marriage and the Family 53, 871-884.

Train, K., 2003. Discrete choice methods with simulation. Cambridge University Press.

Van Houtven, C., Norton, E., 2004. Informal care and health care use of older adults. Journal of Health Economics 23 (6), 1159-1180.

Van Soest, A., 1995. Structural models of family labor supply; a discrete choice approach. The Journal of Human Resources 30, 63-88.

Van Soest, A., Stancanelli, E., 2010. Does income taxation affect partners' household chores, document de travail de OFCE.

Waite, L., Harrison, S., 1992. Keeping in touch: How women in mid-life allocate social contacts among kith and kin. Social Forces 70, 637-655.

Wolf, D., Soldo, B., 1994. Married women's allocation of time to employment and care of elderly parents. The Journal of Human Resources 29 (4), 1259-1276. 


\section{A Logit equilibrium}

Section 6.1.1 explains the noncooperative logit equilibrium, which is a generalization of the Nash equilibrium and deals with 'noisy decisions' made by bounded-rational siblings. This equilibrium concept extends the model for only children described in section 3 , to a game theoretic framework with two players.

In section 6 we have two siblings, $i$ and $j$ who can choose between 12 alternatives. Therefore, to obtain the logit equilibrium we have to solve a system of 24 nonlinear equations, the logit response functions. The logit response functions of sibling $i$ are

$$
\begin{aligned}
& p_{i, 1}=\frac{\exp \left(U\left(t_{i, 1} \mid j=1\right) p_{j, 1}+U\left(t_{i, 1} \mid j=2\right) p_{j, 2}+\cdots+U\left(t_{i, 1} \mid j=12\right) p_{j, 12}\right)}{\sum_{k=1}^{12} \exp \left(\sum_{m=1}^{12} U\left(t_{i, k} \mid j=m\right) p_{j, m}\right)} \\
& p_{i, 2}=\frac{\exp \left(U\left(t_{i, 2} \mid j=1\right) p_{j, 1}+U\left(t_{i, 2} \mid j=2\right) p_{j, 2}+\cdots+U\left(t_{i, 2} \mid j=12\right) p_{j, 12}\right)}{\sum_{k=1}^{12} \exp \left(\sum_{m=1}^{12} U\left(t_{i, k} \mid j=m\right) p_{j, m}\right)} \\
& \vdots \\
& p_{i, 12}=\frac{\exp \left(U\left(t_{i, 12} \mid j=1\right) p_{j, 1}+U\left(t_{i, 12} \mid j=2\right) p_{j, 2}+\cdots+U\left(t_{i, 12} \mid j=12\right) p_{j, 12}\right)}{\sum_{k=1}^{12} \exp \left(\sum_{m=1}^{12} U\left(t_{i, k} \mid j=m\right) p_{j, m}\right)}
\end{aligned}
$$

The logit response functions of sibling $j$ are

$$
\begin{aligned}
& p_{j, 1}=\frac{\exp \left(U\left(t_{j, 1} \mid i=1\right) p_{i, 1}+U\left(t_{j, 1} \mid i=2\right) p_{i, 2}+\cdots+U\left(t_{j, 1} \mid i=12\right) p_{i, 12}\right)}{\sum_{k=1}^{12} \exp \left(\sum_{m=1}^{12} U\left(t_{j, k} \mid i=m\right) p_{i, m}\right)} \\
& p_{j, 2}=\frac{\exp \left(U\left(t_{j, 2} \mid i=1\right) p_{i, 1}+U\left(t_{j, 2} \mid i=2\right) p_{i, 2}+\cdots+U\left(t_{j, 2} \mid i=12\right) p_{i, 12}\right)}{\sum_{k=1}^{12} \exp \left(\sum_{m=1}^{12} U\left(t_{j, k} \mid i=m\right) p_{i, m}\right)} \\
& \vdots \\
& p_{j, 12}=\frac{\exp \left(U\left(t_{j, 12} \mid i=1\right) p_{i, 1}+U\left(t_{j, 12} \mid i=2\right) p_{i, 2}+\cdots+U\left(t_{j, 12} \mid i=12\right) p_{i, 12}\right)}{\sum_{k=1}^{12} \exp \left(\sum_{m=1}^{12} U\left(t_{j, k} \mid i=m\right) p_{i, m}\right)}
\end{aligned}
$$

These 24 equilibrium conditions have to be solved numerically since there is no closed-form solution. 